GRIPS Discussion Paper 19-02

\title{
Monetary Policy and Financial Exclusion in an Estimated DSGE Model of Sub-Saharan African Economies
}

\author{
Paul Owusu Takyi \\ Roberto León-González
}

April 2019

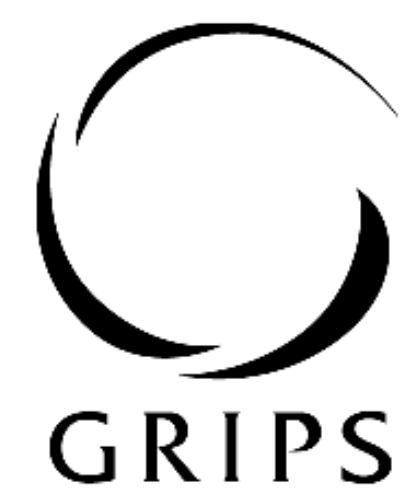

National GRaduate InStitute

FOR POLICY STUDIES

National Graduate Institute for Policy Studies

7-22-1 Roppongi, Minato-ku,

Tokyo, Japan 106-8677 


\title{
Monetary Policy and Financial Exclusion in an Estimated DSGE Model of Sub-Saharan African Economies
}

\begin{abstract}
Paul Owusu Takyi ${ }^{1 *}$ and Roberto Leon-Gonzalez ${ }^{2 *}$
Abstract

This paper examines the effectiveness of monetary policy and its implications for financially included and excluded households in Sub-Saharan African (SSA) economies, using an estimated New-Keynesian DSGE model. The model has financially included ('optimizing') households coexisting with financially excluded ('hand-to-mouth') households. We exploit time series data on four SSA economies, spanning 1985-2016, to estimate the model's parameters through Bayesian inference methods. Our estimation results show that the share of financially excluded households in these economies is relatively small, usually between $35 \%$ and $42 \%$. This finding suggests that previous efforts to enhance financial inclusion in SSA have contributed to a general lowering of the cost of financial market participation. Our results also indicate that the monetary authorities in SSA countries have targeted inflation more aggressively than output growth. Further, the results of our Bayesian impulse response analysis suggests that a positive monetary policy shock does perform its intended role of significantly reducing inflation and output, despite a sizeable fraction of the population is financially excluded. Additionally, we find that a contractionary monetary policy tends to have differentiated impacts; it decreases consumption of financially excluded households more than that of financially included ones. The results reveal that financially included households are able to absorb shocks, and thus can smooth consumption more effectively than financially excluded households. Consequently, given that financially included households are better positioned to address shocks, it is recommended that monetary authorities in developing countries place greater emphasis on output growth relative to inflation. That shifting emphasis could support the stabilization of income, which would enable financially excluded households to smooth consumption. In addition, efforts to ensure full financial inclusion are recommended so that monetary policy can more fully achieve its objectives.
\end{abstract}

Keywords: Monetary Policy, Financial exclusion, DSGE, Bayesian Estimation JEL Classification: E44, E50, E52

\footnotetext{
*National Graduate Institute for Policy Studies (GRIPS), Tokyo, Japan. Email: [1] potakyi2005@gmail.com
} [2] rlg@grips.ac.jp 


\section{Introduction}

Household participation in the financial sector (financial inclusion) is receiving significant empirical and policy attention from major international and development organizations. Mainstream empirical accounts on financial economics suggest that financial inclusion both maximizes societal welfare (by expanding options for safe borrowing and saving practices) and increases credit accessibility and opportunities for investment in the productive sectors of an economy. Those accounts argue that, under conditions of adequate institutional support and extensive stakeholder consultation, the gains from pursuing financial inclusion strategies (1) facilitate attainment of macroeconomic goals including output growth, poverty reduction, bridging of income inequality, and price stability; and (2) enhance the prospects for sustained economic growth (Beck et al. 2007). Probably inspired by those gains, many developing countries in Sub-Sahara Africa (hereinafter SSA) have made a commitment to place a priority on financial inclusion, mainly through the adoption of mobile money technology and increased utilization of microfinance services initiatives. Those efforts have led to substantial financial sector improvements, increasing individual and household access to finance and ultimately enhancing livelihood (Papadavid, 2016). In light of the above, it is clear that formal financial services accessibility plays a significant role in increasing household welfare.

Generally, it is argued that financial access allows households to smooth consumption and build capital over time so as to promote business creation, which in turns helps to improve the livelihood of members of society (Demirguc-Kunt \& Levine, 2009). The role of formal financial services accessibility may be better appreciated if consideration is given to the fact that most businesses in SSA are microenterprises that are subject to household uncertainties. When households are faced with temporary fluctuations in their real income (income shocks), those with access to formal financial services can smooth consumption. One form of income shock is a change in nominal interest rate (monetary policy shock) by central banks. A rise in this rate has the potential to decrease not only inflation but also productivity and employment. Consequently, the consumption of both financially included and excluded households are vulnerable to such policy alteration, through its negative impact on disposable income, although that of financially excluded households is not directly affected. Admittedly, since the former can borrow or tap into their previous savings, their consumption profiles are less likely to be affected. That is, financially included households can adjust their savings and investment decisions to partially protect their consumption from the volatility of their (real) income in a way that financially excluded households are not positioned to do (Mehrotra \& Nadhanael, 2016).

However, it may have to be conceded that even with limited or no access to the formal financial sector, financially excluded households can also smooth consumption through semi-formal and informal financial sources as the financially included ones. As a consequence, and in a rather unsurprising fashion, the extant literature is replete with accounts of mechanisms and ways through which financially excluded households faced with income shocks can also smooth consumption. Several mechanisms have been identified. As discussed by Mehrotra and Nadhanael (2016), the emergence and adoption

of mobile money technology in SSA have allowed the financially excluded households to perform various financial transactions including borrowing and savings accumulation. 
Besides, financially excluded households are also able to obtain loans from microfinance institutions, informal lenders, family, and friends allowing for consumption smoothing, although the interest rate on those loans can be relatively higher. As another medium for fending-off income volatilities, financially excluded households can accumulate savings in the form of land or jewelry. As noted by Resenzweig and Woldpin (1993), livestock and other farm assets could also be traded in a way that allow for consumption smoothing.

Despites all the above characterizations, the reality is that a sizeable portion of population in SSA are effectively excluded from the financial sector. For these group, they neither save nor borrow through formal, semi-formal, or informal means. In effect, the population in this group simply live by 'hand-to-mouth' and on subsistent basis. The implication of such a situation is that they may not be able to smooth consumption when they are faced with income shocks. In response to the prospects of such persons falling on non-cash savings during income shocks, Mehrotra and Nadhanael (2016) were unequivocal when they suggested that, if there are greater negative shocks to an economy, savings in the form of assets other than cash may not even be helpful to smooth consumption much. Indeed, data from World Bank Global Financial Inclusion database (2018) indicates that close to $60 \%$ of adult population who are within the labor force bracket in SSA did not save by any means in the previous year (2017), including placing cash under a mattress or through asset accumulation. Also, about $53 \%$ of those population in SSA hold no account at a bank or any other type of financial institution as of 2017. Figure 1 shows the saving behavior and financial account holding of adult population who are within the labor force bracket in Ghana, Gabon, Lesotho, and Mauritius. It can be seen that, clearly, a sizeable portion of these adult population have no savings in these countries, almost between 36\% and 60\%. Moreover, with the exception of Mauritius, a considerable portion of those population (between 36\% and 46\%) in Ghana, Gabon, and Lesotho hold no account at a bank or any other type financial institution.

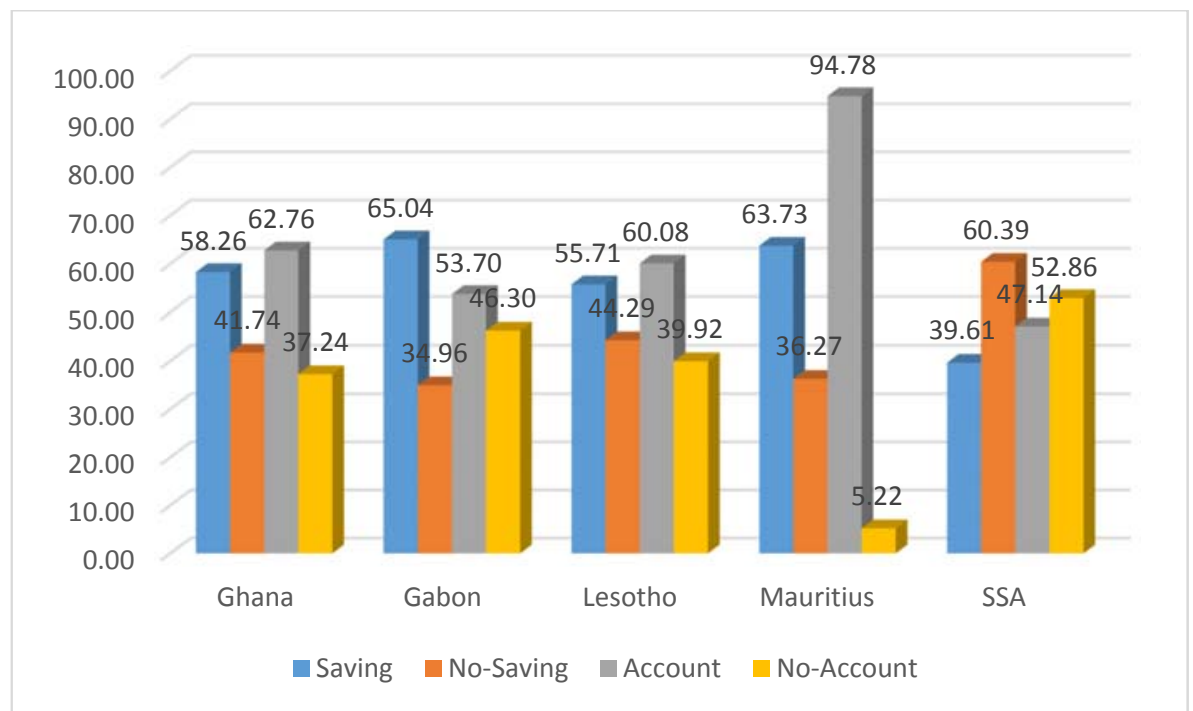

Figure 1: Savings behavior and financial account holdings of adult population in the labor force (\% age $15+$ ).

Source: Authors construction using data from World Bank Global Financial Inclusion database, 2018 
Given the above insights, it seems natural to expect that more studies would have analyzed the welfare (consumption) of these distinct groups of household when they are faced with income shocks. However, very few studies (both theoretical and empirical) have specifically analyzed the implications of monetary policy shock for these households. Those that did, including Conenen and Straub (2005), Ratto et al. (2009), Di Bartolomeo et al. (2011) and Iyer (2016), studied regions outside of SSA, where financial exclusion appears to be the norm rather than the exception. Moreover, most of these studies tend to place emphasis on only aggregate variables rather than disaggregate variables including consumption, which could be used directly as a measure of welfare for those households, although those studies do report and display the heterogeneous dynamics. These observations motivate the focus of this paper to examine the resilience of financially excluded and included households in SSA when they are faced with income-related shocks, especially monetary policy shock.

The first research question here then is: how does monetary policy shock affect the consumption (welfare) of financially excluded households, compared with that of financially included ones?

In addition to those observations and related questions on the nature and conditions of households, the presence of financially excluded households in an economy in itself is also important in the way monetary policies are conducted. For instance, as Mankiw (2000) suggested, economic models that allow for the presence of financially excluded households (basically, 'hand-to-mouth' households) are to be preferred over economic models with representative households. By extension, policymakers need to be interested in differentiated households and how they affect the conception of their policy interventions. Following this proposal, which has mostly been received favorably, many studies including Gali et al. (2004), Conenen and Straub (2005), Gali et al. (2007), Bilbie (2008), Forni et al. (2009), among others have attempted to incorporate financially excluded households. A fundamental limitation of these genre of literature has been the limited focus on the implications of financially excluded households for the conduct of monetary policy (Galí et al., 2004). As noted by Galí et al., (2004), the inclusion of financially excluded households in an otherwise standard dynamic sticky price models can change the properties of the widely used interest rate rules in the pursuit of monetary policy. They noted that the presence of financially excluded households in such models requires the inflation weight in a Taylor-type monetary policy rule to be well above unity. In other words, central banks are expected to be tough-nosed in tackling inflation. We thus, also intend to empirically verify this theoretical predictions in this paper for the case of SSA where financially exclusion is largely in existence.

Moreover, the effectiveness of monetary policy is also affected by the presence of financially excluded households in an economy. In both developed and developing countries most central banks use standard new-Keynesian macroeconomic models for policy analysis and forecasting. In such models the transmission mechanism of monetary policy (a Taylor type monetary policy) largely depends on private investment being interest elastic. Thus, an increase in the monetary policy interest rate induces a decrease in private investment and vice versa. In the end, real economic activities (real output) and inflation are affected. Therefore, if there are a large share of financially excluded households in an economy, the interest elasticity of private spending would be reduced (Brownbridge, et al., 2017). 
The combined effect of above characterizations of monetary policy framework is that when a sizeable portion of the population is excluded from the formal financial sector, the interest rate channel of monetary policy is likely to be weak due to low-interest elasticity of private investment. As a result, monetary policy can be ineffective. Thus, it is imperative to determine whether monetary policy is effective or not in such an environment.

These observations lead us to our second research question: what is the role of monetary policy in an economy where a sizeable fraction of the population is financially excluded?

The contribution of this paper is twofold. We apply New-Keynesian Dynamic Stochastic General Equilibrium (NK-DSGE) model to [1] perform a detailed analysis of heterogeneous dynamics with specific reference to monetary policy shock as well as other structural shocks, and [2] to analyze the effectiveness of monetary policy in an economy where a sizeable proportion of the population is financially excluded. The result is an empirical exploration of the above research questions through the lens of an estimated DSGE model that has financially excluded ('hand-to-mouth') households coexisting with financially included ('optimizing') ones. We estimate this model for four middle-income (developing economies) countries in SSA, namely: Ghana, Gabon, Lesotho, and Mauritius. The choice of these four countries is primarily in response to data convenience. We reason here that these countries are categorized as middle-income countries with similar economic characteristics and thus face similar inflation and growth uncertainties. This provides a basis for a distinguishable statistical differentiation between the effects of monetary policy on key macroeconomic variables.

We identify and examine the role/effectiveness and the impact of monetary policy shock on households in these (SSA) economies. Specifically, we analyze the impacts of monetary policy shock on financially included and excluded households and identify the role that monetary policy generally plays in these economies. Observation from our literature review suggests that few studies have estimated such models to pursue those goals for $\mathrm{SSA}^{3}$.

Previewing our results, we find that the estimated share of financially excluded households is relatively small for all the countries, although there is some degree of country-level heterogeneity. Comparatively, the estimated values indicate that Lesotho has a higher level of financial inclusion followed by Mauritius, Ghana, and Gabon. This finding suggests that previous efforts to enhance financial inclusion in SSA have contributed to a general lowering of the cost of financial market participation

Also, we find that financially included households are able to absorb shocks, and thus can smooth consumption more effectively than financially excluded households. In particular, contractionary monetary policy decreases the consumption of the financially excluded households more than that of the financially included ones. By extension, the outcome signals the fact that whereas financially excluded households suffer more from 'unfavorable innovations' and benefit less from 'favorable innovations', the reverse holds for those enjoying financial inclusion.

Further, our results show that monetary authorities in SSA aggressively targeted lower levels of inflation relative to output growth over our sample period. Evidently, the

\footnotetext{
${ }^{3}$ To the best of our knowledge, our paper is the first to estimate that model for Ghana, Gabon, Mauritius, and Lesotho.
} 
inflation weight in the Taylor rule is found to be far above unity, confirming what Galí et al. (2004) have documented in the literature using calibration.

Finally, we find that monetary policy is effective in SSA economies despite a sizeable fraction of the population being excluded from the formal financial sector. In particular, contractionary monetary policy brings about a fall in inflation and other real variables including output, employment, consumption, and investment.

The remainder of this paper is structured as follows. The next section presents the model which we proceed to estimate. Section 3 explains our estimation procedure and the data used. Section 4 discusses the results, and Section 5 concludes.

\section{The Model}

The model adopted here closely follows a standard New-Keynesian DSGE model featuring the so-called 'rule-of-thumb' or 'hand-to-mouth' consumers developed by Furlanetto and Seneca (2012). The model originally has only one structural shock (i.e., productivity shock). So we augment it by introducing four (4) additional structural shocks, namely: monetary policy shock; preference shock; labor supply shock; and price markup shock. It is important to note that except for the structural shocks all the first-order conditions, as well as the log-linearized equations are the same as in Furlanetto and Seneca (2012) and Gali et al. (2007).

\subsection{Households}

There are two kinds of households: a fraction $\lambda$ of the households are financially excluded. These households do not have access to the formal financial market (and are indexed by ' $r$ ', for following 'rule-of thumb' or 'hand-to-mouth' behavior). They neither save nor borrow: they simply spend their disposable income in each period. The remaining fraction $(1-\lambda)$ of the households are financially included: that is they have access to the formal financial market (indexed by $O$, for 'optimizing'). This group of households chooses plans for consumption, saving, investment, and bond holdings to maximize their lifetime utility. Each household maximizes a lifetime identical intertemporal utility function given by:

$$
E_{t} \sum_{k=0}^{\infty} \beta^{k} U_{k+t}
$$

where $\beta \in(0,1)$ is the subjective discount factor, and the identical instantaneous utility function is given by:

$U_{t}^{i}=\varepsilon_{t}^{b}\left(\log \left(C_{t}^{i}-h C_{t-1}^{i}\right)-\frac{\varepsilon_{t}^{l}}{1+\phi}\left(N_{t}^{i}\right)^{1+\phi}\right)$,

where $i \in(o, r)$ denotes the type of households. Here, $C_{t}^{i}$ represents the household's real consumption at time $t, C_{t-1}^{i}$ is aggregates consumption at time $t, N_{t}^{i}$ is the hours worked at time $t$, and $\phi>0$ denotes the inverse of the Frisch labor elasticity. The level of consumption habit is represented by the parameter $h$ and is external to the households. 


\subsubsection{Financially included household utility maximization}

Financially included households maximize their utility given by:

$$
U_{t}^{o}=\varepsilon_{t}^{b}\left(\log \left(C_{t}^{o}-h C_{t-1}^{o}\right)-\frac{\varepsilon_{t}^{l}}{1+\phi}\left(N_{t}^{o}\right)^{1+\phi}\right),
$$

subject to the following budget constraint:

$$
P_{t}\left(C_{t}^{o}+I_{t}^{o}\right)+\left(1+R_{t}\right)^{-1} B_{t+1}^{o}=W_{t} N_{t}^{o}+R_{t}^{k} K_{t}^{o}+B_{t}^{o}+D_{t}^{o}-P_{t} T_{t}^{r}-F_{t}
$$

as well as capital accumulation expressed as:

$$
K_{t+1}^{o}=(1-\delta) K_{t}^{o}+\Phi\left(\frac{I_{t}^{o}}{K_{t}^{o}}\right) K_{t}^{o}
$$

Here, $P_{t}$ denotes the price level, $I_{t}^{o}$ is real investment, $B_{t}^{o}$ is holdings of one-period bonds that yield a gross risk-free interest rate $\left(1+R_{\tau}\right), W_{t}$ is nominal wage, $K_{t}^{0}$ is capital holdings, $R_{r}^{k}$ is the nominal rental rate on the stock of capital rented by the households, $D_{t}^{\rho}$ is the dividend stream from firms, $T_{t}^{o}$ is the real lump-sum tax paid by the households, and $F_{t}$ is a union membership fee. Also, $\varepsilon_{t}^{b}$ and $\varepsilon_{t}^{l}$ represent preference shock (a shock which affects the inter-temporal substitution of households) and labor supply shock, respectively. Both $\varepsilon_{t}^{b}$ and $\varepsilon_{t}^{l}$ are respectively assumed to follow a first-order autoregressive (AR (1)) process with an independently and identically distributed (i.i.d) normal error term as in Smets and Wouters (2003) given by $\varepsilon_{t}^{b}=\rho_{b} \varepsilon_{t-1}^{b}+u_{t}^{b}$, and $\varepsilon_{t}^{l}=\rho_{l} \varepsilon_{t-1}^{l}+u_{t}^{l}$. Moreover, $\delta$ is the depreciation rate and $\Phi($.$) is capital adjustment cost$ function, which has the following properties: $\Phi(\delta)=\delta, \Phi^{\prime}>0, \Phi^{\prime}(\delta)=1$, and $\Phi " \leq 0$.

The first order conditions for the financially included household's problem can be written as:

$$
\begin{aligned}
& 1=\left(1+R_{t}\right) E_{t}\left\{\Lambda_{t, t+1}\right\}, \\
& P_{t} Q_{t}=E_{t}\left\{\Lambda_{t, t+1}\left[R_{t+1}^{k}+P_{t+1} Q_{t+1}\left((1-\delta)+\phi_{t+1}-\left(\frac{I_{t+1}^{o}}{K_{t+1}^{o}}\right) \phi_{t+1}^{\prime}\right)\right]\right\} \\
& Q_{t}=\frac{1}{\Phi^{\prime}\left(I_{t}^{o} / K_{t}^{o}\right)} \\
& \Lambda_{t, t+1}=\beta\left\{\frac{\varepsilon_{t+1}^{b}}{\varepsilon_{t}^{b}} \frac{P_{t}}{P_{t+1}} \frac{\left(C_{t}^{o}-h C_{t-1}^{o}\right.}{\left(C_{t+1}^{o}-h C_{t}^{o}\right)}\right\},
\end{aligned}
$$

where $\phi_{t+1} \equiv \Phi\left(I_{t+1}^{o} / K_{t+1}^{o}\right), \phi_{t+1}^{\prime} \equiv \Phi^{\prime}\left(I_{t+1}^{o} / K_{t+1}^{o}\right), \Lambda_{t, t+1}$ is the stochastic discount factor, and $Q_{t}$ is the (real) shadow value of capital (Tobin's $Q$ ). Here, the elasticity of investment-capital ratio with respect to $Q$ is given by $-(1 /(\Phi "(\delta) \delta))=\eta$. 


\subsubsection{Financially excluded household utility maximization}

Financially excluded households are unable to smooth consumption in the face of fluctuations in their labor income. Thus, at each period they solve a static problem and therefore maximize their period utility, given by:

$$
U_{t}^{r}=\varepsilon_{t}^{b}\left(\log \left(C_{t}^{r}-h C_{t-1}^{i r}\right)-\frac{\varepsilon_{t}^{l}}{1+\phi}\left(N_{t}^{r}\right)^{1+\phi}\right),
$$

subject to the following budget constraint:

$$
P_{t} C_{t}^{r}=W_{t} N_{t}^{r}-P_{t} T_{t}^{r}-F_{t}
$$

The first order condition for the financially excluded households yields:

$C_{t}^{r}=\frac{W_{t} N_{t}^{r}}{P_{t}}-T_{t}^{r}-\frac{F_{t}}{P_{t}}$

\subsection{Aggregation}

Aggregate consumption, hours worked, and tax are given as a weighted average of the corresponding variables for each type of households, as follows:

$$
\begin{aligned}
& C_{t}=\lambda C_{t}^{r}+(1-\lambda) C_{t}^{o} \\
& N_{t}=\lambda N_{t}^{r}+(1-\lambda) N_{t}^{o} \\
& T_{t}=\lambda T_{t}^{r}+(1-\lambda) T_{t}^{o}
\end{aligned}
$$

Also, aggregate capital stock, investment, bonds, and dividends are given respectively as $K_{t}=(1-\lambda) K_{t}^{o}, I_{t}=(1-\lambda) I_{t}^{o}, B_{t}=(1-\lambda) B_{t}^{o}$, and $D_{t}=(1-\lambda) D_{t}^{o}$.

\subsection{Firms}

Firms are divided into two groups of producers: final goods producer firms and intermediate goods producer firms. The goods from the intermediate firms are used as inputs by the perfectly competitive final goods producers firms.

\subsubsection{Final goods producer firms}

Final goods producer firms produce a final good $Y_{t}$ and sell it in a perfectly competitive market. The final good is a composite of a continuum of differentiated intermediate goods $X_{t}(j), j \in[0,1]$ with a constant returns technology given by:

$$
Y_{t}=\left(\int_{0}^{1} X_{t}(j)^{\frac{\varepsilon-1}{\varepsilon}} d j\right)^{\frac{\varepsilon-1}{\varepsilon}}
$$

where $X_{t}(j)$ denotes the quantity of the intermediate good $j$, and $\varepsilon>1$ represents the elasticity of substitution between differentiated intermediate goods. The final goods producer firms choose the optimal amount of each intermediate good to maximize their 
profit, which is the difference between revenues and costs taken as given price of the final good $P_{t}$ given by:

$$
\Pi_{t}=P_{t} Y_{t}-\int_{0}^{1} P_{t}(j) X_{t}(j) d j
$$

where $P_{t}(j)$ is the price of $j^{\text {th }}$ intermediate good. The solution of the firm's profit maximization yields the set of demand function:

$$
X_{t}(j)=\left(\frac{P_{t}(j)}{P_{t}}\right)^{-\varepsilon} Y_{t}
$$

and a zero-profit condition expressed as:

$$
P_{t}=\left(\int_{0}^{1} P_{t}(j)^{1-\varepsilon} d j\right)^{\frac{1}{1-\varepsilon}}
$$

\subsubsection{Intermediate goods producer firms}

All intermediate goods producer firms use the same production function. The production function for producing an intermediate good $j$ is given by:

$Y_{t}(j)=K_{t}(j)^{\alpha}\left(A N_{t}(j)\right)^{1-\alpha}$

where $A_{t}$ is labor-augmenting technology shock, $K_{t}(j)$ and $N_{t}(j)$ respectively represent capital and labor services hired by firm $j$, and $0 \leq \alpha \leq 1$ is the share of capital to output. The technology shock is assumed to follow an AR (1) process with an i.i.d normal error term given by $a_{t}=\rho_{a} a_{t-1}+u_{t}^{a}$. Firm's cost minimization problem implies an optimality condition written as:

$$
\frac{K_{t}(j)}{N_{t}(j)}=\left(\frac{\alpha}{1-\alpha}\right)\left(\frac{W_{t}}{R_{t}^{k}}\right)
$$

Thus, real marginal cost, which is common to all firms, can be written as:

$$
M C_{t}=\frac{1}{\Theta}\left(\frac{R_{t}^{k}}{P_{t}}\right)^{\alpha}\left(\frac{W_{t}}{P_{t} A_{t}}\right)^{1-\alpha}
$$

where $\Theta=(1-\alpha)^{1-\alpha} \alpha^{\alpha}$

\subsection{Price Setting}

In each period, the intermediate goods producer firms in the economy set nominal prices according to a stochastic time dependent rule proposed by Calvo (1983). A fraction of the firms are able to set a new price $P_{t}^{*}$ with probability $1-\theta$ in each period. Thus, only a fraction $1-\theta$ of the firms are able to reset their prices while the prices of the remaining fraction $\theta$ are unchanged. The maximization problem of a $j^{\text {th }}$ firm is given by:

$$
\max _{P_{t}^{*}} E_{t} \sum_{k=0}^{\infty} \theta^{k} E_{t}\left\{\Lambda_{t, t+k} Y_{t}(j)\left[P_{t}^{*}-\varepsilon_{t+k}^{p} P_{t+k} M C_{t+k}\right]\right\}
$$

subject to: 


$$
Y_{t+k}(j)=X_{t+k}(j)=\left(\frac{P_{t}^{*}}{P_{t+k}}\right)^{-\varepsilon} Y_{t+k}
$$

The first order condition for the firm's problem can be written as:

$$
\sum_{k=0}^{\infty} \theta^{k} E_{t}\left\{\Lambda_{t, t+k} Y_{t+k}(j)\left[P_{t}^{*}-\frac{\varepsilon}{\varepsilon-1} \varepsilon_{t+k}^{p} P_{t+k} M C_{t+k}\right]\right\}=0
$$

where $\varepsilon_{t+k}^{p}$ is price mark-up shock common to all firms; it is assumed to follow an AR (1) process with an i.i.d normal error term given by $\varepsilon_{t}^{p}=\rho_{p} \varepsilon_{t-1}^{p}+u_{t}^{p}$. Finally, aggregate price level equation is described by:

$P_{t}=\left[\theta P_{t-1}^{1-\varepsilon}+(1-\theta)\left(P_{t}^{*}\right)^{1-\varepsilon}\right]^{\frac{1}{1-\varepsilon}}$

\subsection{Labor Union}

Nominal wages are set by a continuum of labor unions, index by $z \in[0,1]$, each representing a continuum of workers. A fraction $\lambda$ of the workers are financially excluded and a fraction $(1-\lambda)$ are financially included. The wage rate for the members of each union is set by that union. The same type of labor services are provided by all workers in the union. The aggregate of labor services of members in the union is the labor service supplied by each union, $N_{t}(z)$. Also, any firm's production function is a DixitStiglitz aggregate of the labor services provided by the unions (Furlanetto \& Seneca, 2012). Thus, any union faces the following demand schedule:

$$
N_{t}(\mathrm{z})=\left(\frac{W_{t}(\mathrm{z})}{W_{t}}\right)^{-\varepsilon_{w}} N_{t}^{d}
$$

where $N_{t}^{d}$ is total demand for labor and $\mathcal{E}_{w}$ denotes the elasticity of substitution between different types of labor. The aggregator for household hours worked $N_{t} \equiv \int_{0}^{1} N_{t}^{d}(z) d z$ can be combined with equation (18) to yield the total amount of hours supplied for any household:

$$
N_{t} \equiv N_{t}^{d} \int_{0}^{1}\left(\frac{W_{t}(z)}{W_{t}}\right)^{-\varepsilon_{w}} d z .
$$

An equal share of the wage-adjustment cost is covered by each member of the union in a form of a union membership fee, $\left(F_{t}\right)$. The wage adjustment cost faced by unions is assumed to be convex ,following Rotemberg (1982). Therefore, a member of the union at any time $t$ pays a nominal fee given by:

$$
F_{t}(z)=\frac{\phi_{w}}{2}\left[\frac{W_{t}(z)}{W_{t-1}(z)}-1\right]^{2} W_{t} N_{t}
$$

where $\phi_{w}>0$ is the size of the wage-adjustment costs parameter.

A representative union in each period chooses $W_{t}(\mathrm{z})$ to maximize the following: 


$$
\max _{W_{t}(z)} E_{t} \sum_{k=0}^{\infty} \beta^{k}\left[\lambda U_{t+k}^{r}+(1-\lambda) U_{t}^{o}\right]
$$

subject to the two budget constraints above (equations 2 and 8), labor demand function (equation 8), and the aggregate union fee $F_{t}=\int_{0}^{1} F_{t}(z) d z$, where $F_{t}(z)$ is given by equation 19. The equilibrium condition, imposing a symmetry so that $W_{t}(z)=W_{t}$ and $N_{t}(z)=N_{t}$ for all $z$, can be written as:

$$
\begin{aligned}
0= & \left(M R S_{t}\right)^{-1} \frac{W_{t}}{P_{t}}\left[\left(1-\varepsilon_{w}\right)-\phi_{w}\left(\Pi_{t}^{w}-1\right) \Pi_{t}^{w}\right] N_{t}^{1+\phi}+\varepsilon_{w} N_{t}^{1+\phi} \\
& +\beta \phi_{w} E_{t}\left\{\left(M R S_{t+1}\right)^{-1}\left(\Pi_{t+1}^{w}-1\right) \Pi_{t+1}^{w} \frac{W_{t+1}}{P_{t+1}} N_{t+1}^{1+\phi}\right\}
\end{aligned}
$$

where $\Pi_{t}^{w}=W_{t} / W_{t-1}$ and $M R S_{t}$ is the weighted average of the marginal rate of substitution between labor hours and consumption of each type of household or worker given by:

$\left(M R S_{t}\right)^{-1}=\lambda\left(M R S_{t}^{r}\right)^{-1}+(1-\lambda)\left(M R S_{t}^{o}\right)^{-1}=\left(\varepsilon_{t}^{l} N_{t}^{\phi}\right)^{-1}\left[\lambda\left(C_{t}^{r}-h C_{t-1}^{r}\right)^{-1}+(1-\lambda)\left(C_{t}^{o}-h C_{t-1}^{o}\right)^{-1}\right]$

Labor services (hours worked) is assumed to be identical across all households implying that both types of households supply the same amount of labor, that is, $N_{t}=N_{t}^{o}=N_{t}^{r}$.

\subsection{The Central Bank (Monetary Policy)}

There is a monetary authority who controls monetary policy by setting the nominal interest rate $r_{t}$ according to a Taylor (1993) rule expressed as:

$$
\frac{R_{t}}{R_{s s}}=\left(\frac{R_{t-1}}{R_{s s}}\right)^{\rho_{r}}\left[\left(\frac{\pi_{t}}{\pi_{s s}}\right)^{\phi_{\pi}}\left(\left(\frac{Y_{t}}{Y_{s s}}\right) /\left(\frac{Y_{t-1}}{Y_{s s}}\right)\right)^{\phi_{y}}\right]^{\left(1-\rho_{r}\right)} \varepsilon_{t}^{m}
$$

where, $\rho_{r}$ denotes the degree of interest rate smoothing, $\phi_{\pi}$ and $\phi_{y}$ are the weights the central bank places on inflation and output growth respectively, and $\varepsilon_{t}^{m}$ represents a monetary policy shock which is assumed to be exogenous with an i.i.d normal error term written as $\varepsilon_{t}^{m}=u_{t}^{m}$.

\subsection{Equilibrium}

Goods market clearing condition requires aggregate output to be equal to aggregate demand (the sum of aggregate consumption, investment, government spending and union fee), expressed as:

$Y_{t}=C_{t}+I_{t}+G_{t}+F_{t}$

where $G_{t}=\gamma_{G} Y_{t}$ represents government spending, and $\gamma_{G}=G / Y$ is the steady state ratio of government spending to output. It is to be noted that there are adjustments of taxes in every period that guarantee government budget balancedness. 
The first order conditions, the aggregations equations, and the equilibrium condition are log-linearized using first-order Taylor approximation around deterministic and zero-inflation steady states. The model's parameters are then estimated using Bayesian inference methods and the DYNARE 5.1 software for MATLAB is used.

\subsection{Log-linearized equilibrium conditions}

Here, the log-linearized versions of the equilibrium conditions are presented. The first-order Taylor approximation around a zero-inflation steady state is used for some conditions whereas other conditions precisely hold. Note that lower case letters or variables with " $\wedge$ " represent log-deviation with respect to the corresponding steady state values. The following log-linearized equations summarizes the equilibrium dynamics of the model.

\subsubsection{Households}

The financially included households' consumption optimality conditions with equations (4) and (7) combined can be written as:

$c_{t}^{o}=\frac{h}{1+h} c_{t-1}^{o}+\frac{1}{1+h} E_{t}\left(c_{t+1}^{o}\right)-\frac{1-h}{1+h}\left(r_{t}-E_{t}\left(\pi_{t+1}\right)\right)+\frac{1-h}{1+h}\left(\hat{\varepsilon_{t}^{b}}-E_{t}\left(\hat{\varepsilon}_{t+1}^{b}\right)\right)$

The investment equation (equation 6) and it relationship with the equation which describes the dynamics of Tobin's $Q$ (equation 5) can respectively be written as:

$i_{t}-k_{t}=\eta q_{t}$

$q_{t}=-\left[r_{t}-E_{t}\left(\pi_{t+1}\right)\right]+[1-\beta(1-\delta)] E_{t}\left(r_{t+1}^{k}-p_{t+1}\right)+\beta E_{t}\left(q_{t+1}\right)+\varepsilon_{t}^{q}$

where $\varepsilon_{t}^{q}$ is equity premium shock introduced externally to capture the changes in the cost of capital (value of capital installed) that may not come from the stochastic variations in the external finance premium (Smets and Wouters (2003); and Coenen and Straub (2005)). We assume that this shock follows an AR (1) process with an i.i.d normal error term given by $\varepsilon_{t}^{q}=\rho_{p} \varepsilon_{t-1}^{q}+u_{t}^{q}$. The log-linearized version of the capital accumulation equation (equation (3) can be written as:

$k_{t+1}=(1-\delta) k_{t}+\delta i_{t}$

The financially excluded households' consumption optimality condition (equation 9) can be written as:

$c_{t}^{r}=\frac{W N}{P C}\left(w_{t}-p_{t}+n_{t}\right)-\frac{T^{r}}{C} t_{t}^{r}$

Here, it is assumed that the steady consumption is the same for all households i.e. $C=C^{o}=C^{r}$ and as stated before, $n_{t}=n_{t}^{o}=n_{t}^{r}$ likewise $N=N^{o}=N^{r}$. The loglinearization of aggregate variables (real consumption and labor hours) implies that:

$c_{t}=\lambda c_{t}^{r}+(1-\lambda) c_{t}^{o}$

$n_{t}=\lambda n_{t}^{r}+(1-\lambda) n_{t}^{o}$

\subsubsection{Firms}

The familiar equation (New Keynesian Phillips Curve) describing the dynamics of price inflation as a function of the deviations of the average logarithm of mark-up from its steady state level can be obtained from equation 16 and 17 written as: 
$\pi_{t}=\beta E_{t}\left(\pi_{t+1}\right)+\kappa_{p}\left(m c_{t}+\hat{\varepsilon}_{t}^{p}\right)$

where, $\kappa_{p}=\frac{(1-\beta \theta)(1-\theta)}{\theta}, \pi_{t}=p_{t}-p_{t-1}$ is price inflation and $m c_{t}$ is real marginal cost and using equation 15 , we obtain:

$m c_{t}=\left(w_{t}-p_{t}\right)-\left(y_{t}-n_{t}\right)$

Additionally, cost minimization implies the ratio of inputs (capital to labor ratio) given by equation 14 can be written as:

$k_{t}-n_{t}=\left(w_{t}-p_{t}\right)-\left(r_{t}^{k}-p_{t}\right)$

Also, log-linearization of the production function (equation 13) yields:

$y_{t}=\alpha k_{t}+(1-\alpha)\left(a_{t}+n_{t}\right)$

\subsubsection{Labor unions}

The optimality condition following the union's problem (equation 20) yields the familiar New Keynesian Phillips Curve for wage inflation as given below:

$\pi_{t}^{w}=\beta E_{t}\left(\pi_{t+1}^{w}\right)+\kappa_{w}\left[m r s_{t}-\left(w_{t}-p_{t}\right)\right]$

where, $\kappa_{w}=\frac{\varepsilon_{w}-1}{\phi_{w}}, \pi_{t}^{w}=w_{t}-w_{t-1}$ is wage inflation, and $m r s_{t}$ is given by:

$m r s_{t}=\frac{\lambda}{1-h}\left(c_{t}^{r}-h c_{t-1}^{r}\right)+\frac{1-\lambda}{1-h}\left(c_{t}^{o}-h c_{t-1}^{o}\right)+\phi n_{t}+\hat{\varepsilon}_{t}^{l}$

\subsubsection{Equilibrium}

Log-linearizing the market clearing condition (equation 22) yields:

$\left(1-\gamma_{G}\right)=\gamma_{C} c_{t}+\gamma_{I} i_{t}$

where, $\gamma_{C}=\frac{C}{Y}$, and $\gamma_{I}=\frac{I}{Y}$ are the ratio of steady states of real consumption and investment to output, respectively.

\subsubsection{Monetary Authority}

Log-linearization of the monetary policy rule (equation 21) yields:

$r_{t}=\rho_{r} r_{t-1}+\left(1-\rho_{r}\right)\left[\phi_{\pi} \pi_{t}+\phi_{y}\left(y_{t}-y_{t-1}\right)\right]+\varepsilon_{t}^{m}$

\subsubsection{Shock processes}

All shock processes in the set-up are given in a log-linearized form and are assumed to follow an AR (1) process (except for the monetary policy shock) with an i.i.d normal distribution error term with zero mean and its own variance, $\delta_{e}^{2}$ (i.e. $u_{t}^{e} \square N\left(0, \delta_{e}^{2}\right)$, where $e$ is the shock type) written below:

Households' preference shock:

$\hat{\varepsilon_{t}^{b}}=\rho_{b} \hat{\varepsilon}_{t-1}^{l}+u_{t}^{b}$

Labor supply shock: 
$\hat{\varepsilon}_{t}^{l}=\rho_{l} \hat{\varepsilon}_{t-1}^{l}+u_{t}^{l}$

Price mark-up shock:

$\hat{\varepsilon_{t}^{p}}=\rho_{p} \hat{\varepsilon}_{t-1}^{p}+u_{t}^{p}$

Productivity shock

$a_{t}=\rho_{a} a_{t-1}+u_{t}^{a}$

Monetary policy shock

$\varepsilon_{t}^{m}=u_{t}^{m}$

It, therefore, follows from the above that equations 23 to 37, and the shock processes (equations 38 to 42) summarize the equilibrium in the economy.

\subsection{Steady states}

The main steady state equations as implied by the model as in Furlanetto and Seneca (2012) and Gali et al (2007) are summarized below:

$\frac{W N}{P C}=\frac{(1-\alpha)}{u^{p}} \gamma_{C}$, where, $u^{p}=\frac{\varepsilon}{\varepsilon-1}$,

$\gamma_{C}=\frac{C}{Y}=\left(1-\gamma_{G}\right)-\frac{\delta \alpha}{(\rho+\delta) u^{p}}$, where, $\rho=\frac{1}{\beta}-1$

$\gamma_{I}=\frac{I}{Y}=1-\gamma_{G}-\gamma_{C}$

$\frac{T^{r}}{C}=\frac{W N}{P C}-1$

\section{Estimation}

\subsection{Data}

Estimation of the parameters of the DSGE model presented above use quarterly time series data spanning 1985Q1 to 2016Q4 on real Gross Domestic Product (GDP), real households' consumption expenditure, Consumer Price Index (CPI), and nominal interest rate (monetary policy rate/discount rate) for four countries: Ghana, Gabon, Lesotho, and Mauritius.

Following Smets and Wouters (2007), log first difference of real GDP, real consumption, and CPI multiplied by 100 are taken to represent output growth, consumption growth, and inflation respectively. Thus, our observed variables include: output growth, consumption growth, inflation, and interest rate. It is to be noted that quarterly series for real GDP and real consumption are interpolated from their annual counterparts using CPI as an indicator variable, following the technique described in Chow and Lin (1971).

All series are seasonally adjusted except for the nominal interest rate. Series on CPI and nominal interest rate are obtained from IMF International Financial Statistics database, whereas, series on real GDP and real consumption are sourced from the World Bank's World Development Indicators database (2018). The start and period of the dataset is chosen on the basis of data availability. Using the World Bank's classification, 
the four countries are selected from among the middle-income SSA countries, based on data availability.

\subsection{Calibration}

Four of the model's parameters and one steady state variable were calibrated while the remaining parameters were estimated for each country. We calibrated some parameters because the data points were insufficient and chose these four parameters ( $\varepsilon$, $\eta, \varepsilon_{w}$, and $\left.\phi_{w}\right)$. We found that estimating them together with the remaining parameters distorted the convergence diagnostics. Moreover, they were not of major interest to us. Thus, we set $\varepsilon=6, \eta=1, \varepsilon_{w}=4$, and $\phi_{w}=174.7$ using the calibrated values from Furlanetto and Seneca (2012). Also, $\gamma_{G}$, which is the steady ratio of real government expenditure to real GDP, was calibrated using an observed data for each of the country. That is, we computed the long-run average of the ratio of real government expenditure to real GDP from 1985 to 2016 yielding 0.14, 0.18, 0.26, and 0.13 for Ghana, Gabon, Lesotho, and Mauritius respectively. Series on real government expenditure is sourced from the World Bank’s World Development Indicators database (2018).

\section{Results and Discussion}

The prior means and prior distributions, as well as the posterior estimation results of the model's parameters and the six exogenous shocks, are reported in Tables 1 and 2 for pairs of countries: Ghana vs. Gabon, and Lesotho vs. Mauritius. Note that the priors are the same for all the countries unless otherwise stated. In Table 1, the priors in parentheses are for Gabon whereas in Table 2 the priors in the parentheses are for Lesotho.

\subsection{Priors}

The third, fourth, and fifth columns of Tables 1 and 2 give a synopsis of our assumptions on the prior distribution of 24 parameters for each of the four countries. Thus, some of the priors for the parameters are carefully chosen. In choosing the priors, in some cases, the calibrated values of the parameters from Furlanetto and Seneca (2012) and Gali et al. (2007) were used as prior means with an assumed standard deviation, while in other cases we followed the standard literature or are assumed.

In particular, the discount factor and the depreciation rate are assumed to follow a Beta distribution with means 0.99 and 0.025 , and standard deviations 0.002 and 0.003 , respectively. The parameters governing the share of financially excluded households and consumption habit also follow a Beta distribution with means 0.5 and 0.7 , respectively and standard deviations of 0.025 for all the countries, except for Gabon which has a standard deviations of 0.02 each. The prior mean for the fraction of the financially excluded households is consistent with the ones used by Marto (2014), Di Bartolomeo, et al. (2011), Forni, Monteforte, and Sessa (2009) and Coenen and Straub (2005) but differs in standard deviation.

A Gamma distribution is assumed for the coefficient of Frisch labor elasticity with a mean value of 0.5 and a standard deviation equal to 0.01 for Ghana and Gabon, and 0.1 for Lesotho and Mauritius. The parameters governing the share of capital to output and Calvo price stickiness are both assumed to follow a Beta distribution and fluctuate around 
0.33 and 0.75 , respectively. The standard deviation for the former is 0.1 for all the countries, while the later has a standard deviation of 0.01 for Ghana and Gabon, 0.015 for Mauritius, and 0.1 for Lesotho. The standard errors of all the innovations are assumed to follow inverse gamma distribution with mean 0.1 and standard deviation of 2, except for the standard error of the monetary policy shock, which has a mean value of 0.01 for Lesotho. Further, a Beta distribution is assumed for all the persistence parameters of shock, processes with mean 0.5 and standard deviation 0.1 , except that of the technology shock which has a mean of 0.95 and a standard deviation value of 0.002 . Also, the standard deviation of preference shock is 0.01 for Lesotho.

Finally, the degree of interest-rate smoothing parameter is assumed to follow Beta distribution which centers around 0.69 with standard deviation 0.1. As in Smets and Wouters (2003), the parameters governing the weight the central bank places on inflation and output growth are both normally distributed with means 1.7 and 0.26 , and standard deviations 0.25 and 0.015, respectively for Ghana, Gabon, and Mauritius. Similarly, both are normally distributed with means 1.7 and 0.26 but with standard deviations 0.25 and 0.025, respectively for Lesotho.

\subsection{Posterior Estimates}

Given our priors, we estimate the posterior distributions of the parameters using the Metropolis-Hastings algorithm. We run two independent Markov chains with five hundred thousand $(500,000)$ draws and perform the Brooks and Gelman (1998) convergence diagnostics. These results together with the trace plots suggest that the two chains have converged for both univariate and multivariate convergence. Appendix A displays the trace plots of some selected parameters. We report the Bayesian posterior mean estimates of the parameters for the four countries under consideration in the last two columns of Tables 1 and 2. It can be seen that some of the parameters have their posterior estimates closer to their prior means (and similar across countries), indicating consistency between the priors (initial guess) and the information contained in the data. However, other parameters saw the posterior estimates moving far from their priors (and varying across countries), indicating an additional gain of employing the data in our Bayesian technique.

To begin with, the estimates of the fraction of financially excluded households' parameter range from approximately $35 \%$ t to $42 \%$. Specifically, Lesotho registered the lowest estimated value of 34.62\%, followed by Ghana and Mauritius, recording $35.09 \%$ and $36.04 \%$, respectively with Gabon registering the highest value of $41.84 \%$. The variations in the estimates of this parameter for these countries may be explained by the different levels of financial development (financial inclusion) in these countries. In comparison with the findings in the literature, the estimates obtained for all the countries are larger than those estimated by Campbell and Mankiw (1991) for the UK (20.3\%), Canada (22.5\%), and Japan (3.5\%), and than the ones found by Di Bartolomeo et. al, (2011) for Germany (7.5\%), and Italy (9\%). Also, the estimates are close to those of Coenen and Straub (2005), Forni, et al., (2009), and Ratto et al. (2009) for the euro area (35\% to 37\%) and those obtained by Di Bartolomeo et. al, (2011) for the USA (35.4\%), and France (44.2\%). However, they are considerably lower than that of Marto (2014) found for Portugal (57.8\%) It is, therefore, not unreasonable to confirm statistical 
regularity of our estimates as they lie within the range of findings in the empirical literature.

Moreover, considering the parameter governing habit persistence formation of financially included households, the estimated values range from about 0.53 to 0.69 . In particular, Mauritius recorded the highest estimated value, approximately 0.69 , followed by Gabon and Ghana (0.68 and 0.66, respectively) with Lesotho registering the lowest estimated value, 0.53 . The point estimates for all four countries are close to those found by Smet and Wouters (2003), Christiano et al. (2005), and Marto (2014).

The following is a discussion of the parameters characterizing the Taylor rule (Monetary policy). The estimates of the parameter representing the degree of interest-rate smoothing registered a minimum value of about 0.54 and a maximum value of about 0.9. Particularly, Ghana recorded the lowest value for degree of interest-rate smoothing (approximately 0.54), with Gabon registering the highest value (approximately 0.9). Also, the estimate for Mauritius is approximately 0.65 and that for Lesotho is about 0.67. Overall, we find evidence of a moderate degree of interest-rate smoothing for all the countries except for Gabon, which saw a higher degree of interest-rate smoothing.

Again, the response of interest rate to inflation is far greater than unity in the longterm for all the countries; this satisfies the condition noted by Galí e. al., (2004), and is broadly in line with that proposed by Taylor (1993). We find that the central banks in all the countries pursue strict anti-inflationary policies with an inflation coefficient value of about 3.2. Comparatively, the Central Banks of Ghana and Lesotho are the most aggressive towards anti-inflation, followed by Mauritius and Gabon with an estimated value of 3.16 and 3.10, respectively. The finding that Central Bank of Ghana is one of the two countries who are most aggressive towards anti-inflation is not surprising, as Ghana is the only country among the four which is officially operating under inflation targeting monetary policy. This finding is, however, not consistent with the finding by Cantah and Ahiakpor (2017). The authors used Markov Switching model to examine the conduct of monetary policy in Ghana and conclude that the Central Bank of Ghana has not been attentive to price stability, which is the direct opposite of our finding.

Also, the estimates of the response of interest rate to output growth are greater than zero (similar across countries) and are consistent with the one suggested by Taylor (1993). In comparison, the estimated values suggest that the Central Bank of Ghana is the most aggressive towards output growth, followed by Gabon, and Mauritius with Lesotho being the least. Specifically, the coefficient of output growth saw an estimated value of about 0.25 for Ghana, 0.244 for Gabon, 0.243 for Mauritius, and 0.231 for Lesotho. Overall, it can be concluded that central banks in SSA countries have been aggressive towards targeting lower levels of inflation relative to output growth.

Moreover, the estimate of the contribution of capital to output is small for all the countries, approximately 0.05 . Also, the depreciation rate parameter had an estimate which is approximately close to its prior mean for all the countries with little significant variations among the countries; the same can be said for the parameter for discount factor as well as that for the degree of price stickiness. The degree of price stickiness is found to be modest, and the estimates suggest that the time between re-optimizations is around three quarters. Also, the inverse of the Frisch labor elasticity parameter estimate is similar among the four countries with an average of about 0.5 . This average value (0.5) implies that labor-supply elasticity with respect to real wage is in the neighborhood of 2 . This 
means that households in these (SSA) economies largely adjust their labor supply to small changes in their real wage.

In addition, the estimates of all the stochastic processes show considerable degree of persistence and they are similar for all the countries as captured by the autocorrelation parameters. These high and modest persistence estimates for the shocks are consistent with the findings of Smet and Wouters (2003), Coenen and Straub (2005), among others. A notable exception is Lesotho where the autocorrelation parameters estimate of price mark-up shock is less persistence ( $\rho_{p}=0.13$ ). These large (small) estimates indicate that when these economies are faced with the structural shocks, as considered in the model, the impacts would resonate long (soon) after the shock ends.

Finally, the magnitude of the estimates for the standard deviations of the innovations varies considerably among the countries. This means that the relevance of these shocks differs significantly among the four countries. Monetary policy shock saw a larger standard deviation estimates when the model was applied to Ghana (6.07), Lesotho (5.64), Mauritius (4.47), and Gabon (1.09), whereas the standard deviation of the price mark-up shock registered bigger estimate when applied to Lesotho (138.14), Gabon (71.67), Ghana (43.52), and Mauritius (20.71). Also, the standard deviation for preference shock registered larger estimates when the model was applied to Lesotho (31.31), Gabon (25.19), Ghana (19.51), and Mauritius (10.98). Furthermore, the standard deviation estimates for technology shock were 16.72, 9.56, 7.78, and 6.84 for Gabon, Ghana, Lesotho, and Mauritius, respectively. It can be observed that it is only the standard deviation estimates for labor supply shock which had a relatively low variance irrespective of the country the model was applied to. These dynamics in the variance may emanate from differences in the information contained in the data, and the relevance of each structural shock in each of the countries.

\subsection{Bayesian impulse response analysis}

In this section, we examine the impact of each of the structural shocks on selected macroeconomic variables and, most importantly, analyze the role of monetary policy shock in the four economies and its impact on the consumption (welfare) of financially included and excluded households. Revealingly, the impulse response functions are very similar across the four countries, although there is some degree of country-level heterogeneity. Evidently, the responses of output, inflation, consumption, and interest rate to a positive monetary policy shock are displayed in Figure 2 for Ghana, Gabon, Mauritius, and Lesotho. It can be seen that a contractionary monetary policy induces a fall in inflation, output, and consumption in all four countries. Thus, despite a sizeable estimate of the share of financially excluded households in these economies, monetary policy is seen to be still effective, although the magnitude and the impacts of the shock are felt differently by country. Also, the consumption responses of financially included and excluded households to a positive monetary policy shock are displayed in Figure 3. It can be seen that, in all countries, a rise in interest rate reduces the consumption of the financially excluded more than their included counterparts. This is because the latter are able to mitigate the negative effect of the monetary policy shock through their savings in the financial sector, an action which the former are not positioned to undertake.

Given that the responses of the other variables to all the structural shocks in the model are similar across the four countries, we select the following impulse response 
functions as representative for all the countries so as to analyze their impact in those economies. The transmission mechanisms are fully explained. All dynamic responses of the variables depict a one standard deviation shock to all innovations and percentagepoint deviations from their steady state. The blue lines represent the mean impulse responses, while the gray areas indicate the 90\% Highest Posterior Density Intervals (HPDI), the $90 \%$ confidence band.

The response of the selected macroeconomic variables to a contractionary monetary policy shock are displayed in Figure 4. That shock leads to a rise in nominal interest rate of about 0.83 percentage points and gradually decreases to its baseline line value after about 14 quarters. The shock has a negative effect on the economy: that is, the increase in interest rate crowds out investment and aggregate consumption, leading to lower aggregate demand, and the reactions are hump-shaped due to the habit formation parameter in the model. There is an immediate fall in output and inflation of about 3.21 and 0.34 percentage points, respectively. The lower aggregate demand is accompanied by lower employment leading to a fall in disposable income by both financially included and excluded households. This reduction in disposable income translates into lower consumption of both types of households. However, because the financially included households have access to the formal financial market and thus have access to their previous savings, they are able to mitigate the fall in their consumption more than the financially excluded households. It can be seen that, the consumption of financially included households decreases by about 1.72 with a peak of 2.08 percentage points as against about 3.56 with a peak of 3.78 percentage points decrease in consumption of the financially excluded households. In this sense, the former are able to smooth consumption better than the latter, following that shock. It can be concluded that contractionary monetary policy worsens the welfare (measured in terms of consumption) of financially excluded households more than that of financially included ones. Thus, to maximize welfare in the economy through interest rate setting, the central banks together with government authorities need to implement policies to ensure full financial inclusion of their citizenry. 

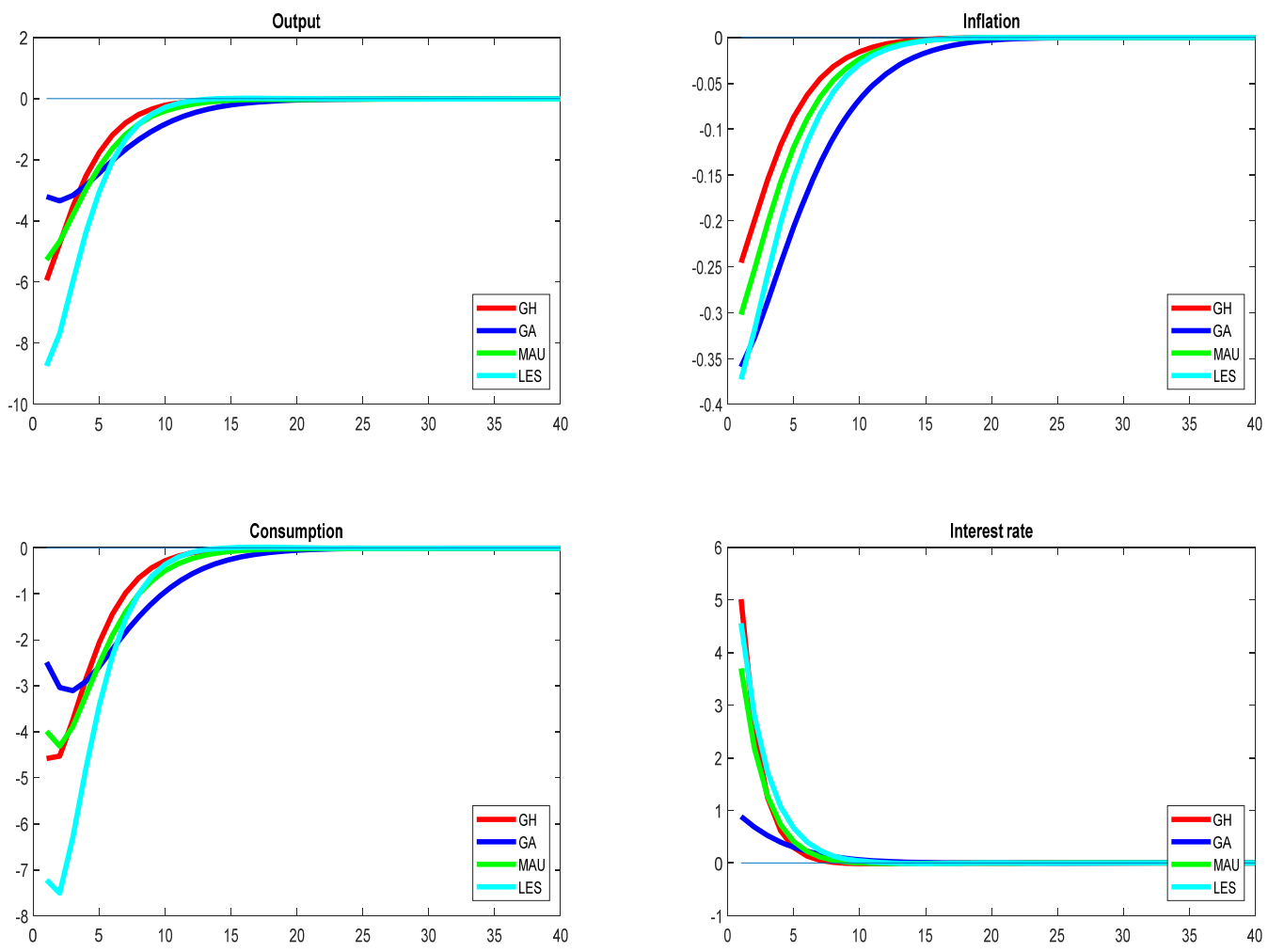

Figure 2: Response of output, inflation, and consumption to monetary policy shock. Note: GH, GA, MAU, and LES stands for Ghana, Gabon, Mauritius, and Lesotho respectively.

Further, Figure 5 displays the impulse response functions of those variables to a positive labor-augmenting total factor productivity shock. That positive shock surges productivity and immediately causes a drop in employment, because producers need to hire less amount of labor to produce the same quantity of output. Consequently, capital become more productive which motivates financially included households to accumulate more of that leading to an increase in investment. A fall in marginal cost, ceteris paribus, due to the positive technology shock leads to a decrease in inflation and a rise in output while real wage increases due to the deflation. The reduction in employment significantly decreases the disposable income of financially excluded households, inducing a reduction in their consumption of about 6.48 percentage points but increases thereafter to a peak of about 15.02 percentage points. However, the consumption of financially included households stays positive or immediately increases by about 6.04 percentage points, peaking at 15.74 percentage points. Consequently, aggregate consumption immediately rises by only 0.81 percentage points on impact. It can be observed that, the monetary authorities become aggressive in accommodating the shock by decreasing the interest rate, leading to a rise increasing aggregate demand to increase employment, though the increase in employment is short-lived. That is, after initial quarters, employment starts rising causing a rise in disposable income leading to an increase in consumption of financially excluded households. Aggregate consumption then rises with a maximum value of about 15.8 percentage points after the sixth quarters. 

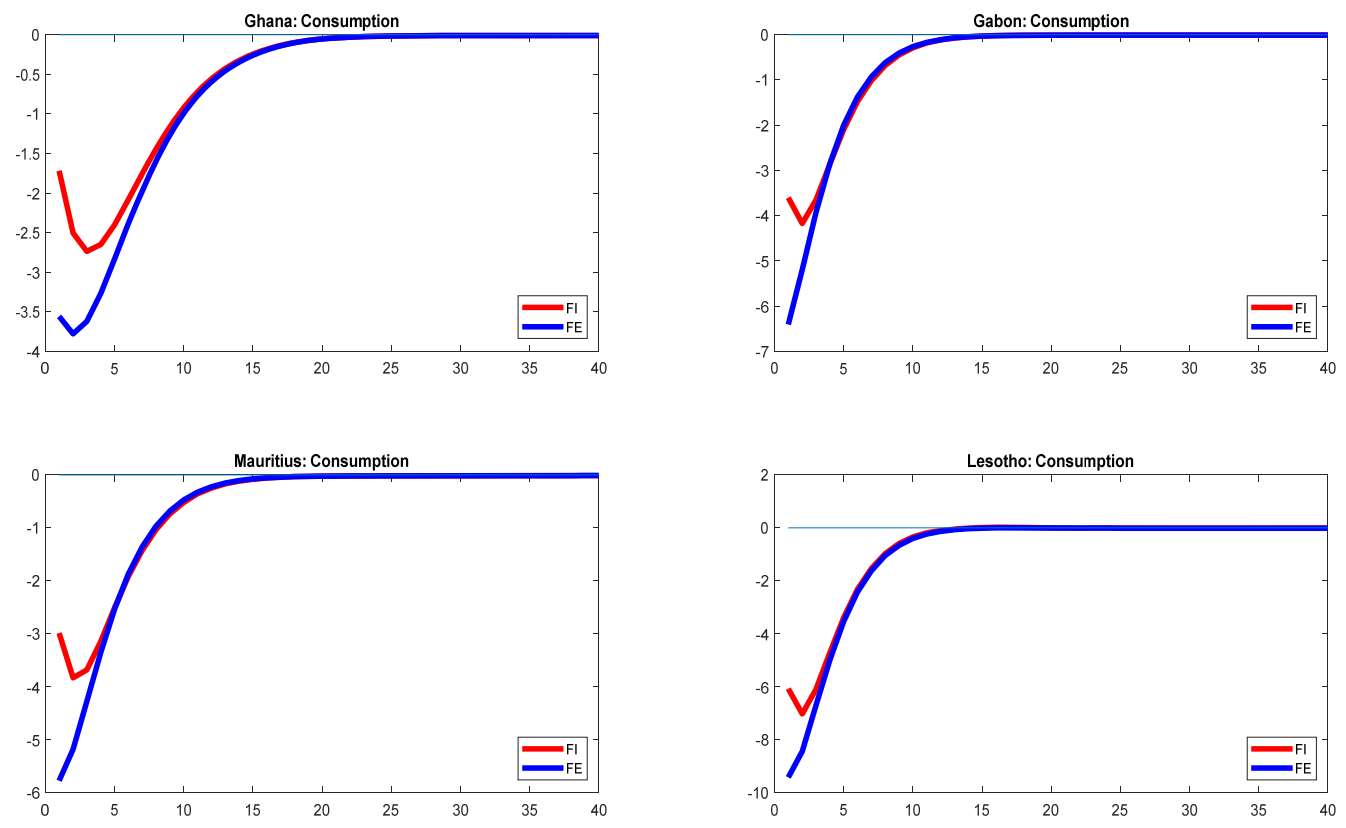

Figure 3: Response of the consumption of financially included and excluded households to a monetary policy shock. Note: FI and FE stands for financially included and financially excluded households, respectively.

Moreover, Figure 6 presents the impulse responses of the select variables to a rise in the price mark-up innovation. Inflation rises and output falls on impact following that shock. The monetary authorities respond to the rise in inflation by raising the nominal interest rate according to the Taylor rule. Also, the presence of inflation and/or high interest rate cause a reduction in consumption of both types of households and a fall in aggregate consumption. Whereas the consumption of financially included households decreases by about 4.45 percentage points that of financially excluded households decreases by about 20.67 percentage points after the second quarter where it reached a peak of about 26.33 percentage points below the steady sate value. The lower aggregate demand induces lower employment in the short-run as evidenced by a reduction in employment of about 13.07 percentage points, while real wage falls due to the rise in inflation. The consumption of financially excluded households is contracted further by lower real wage and employment. 

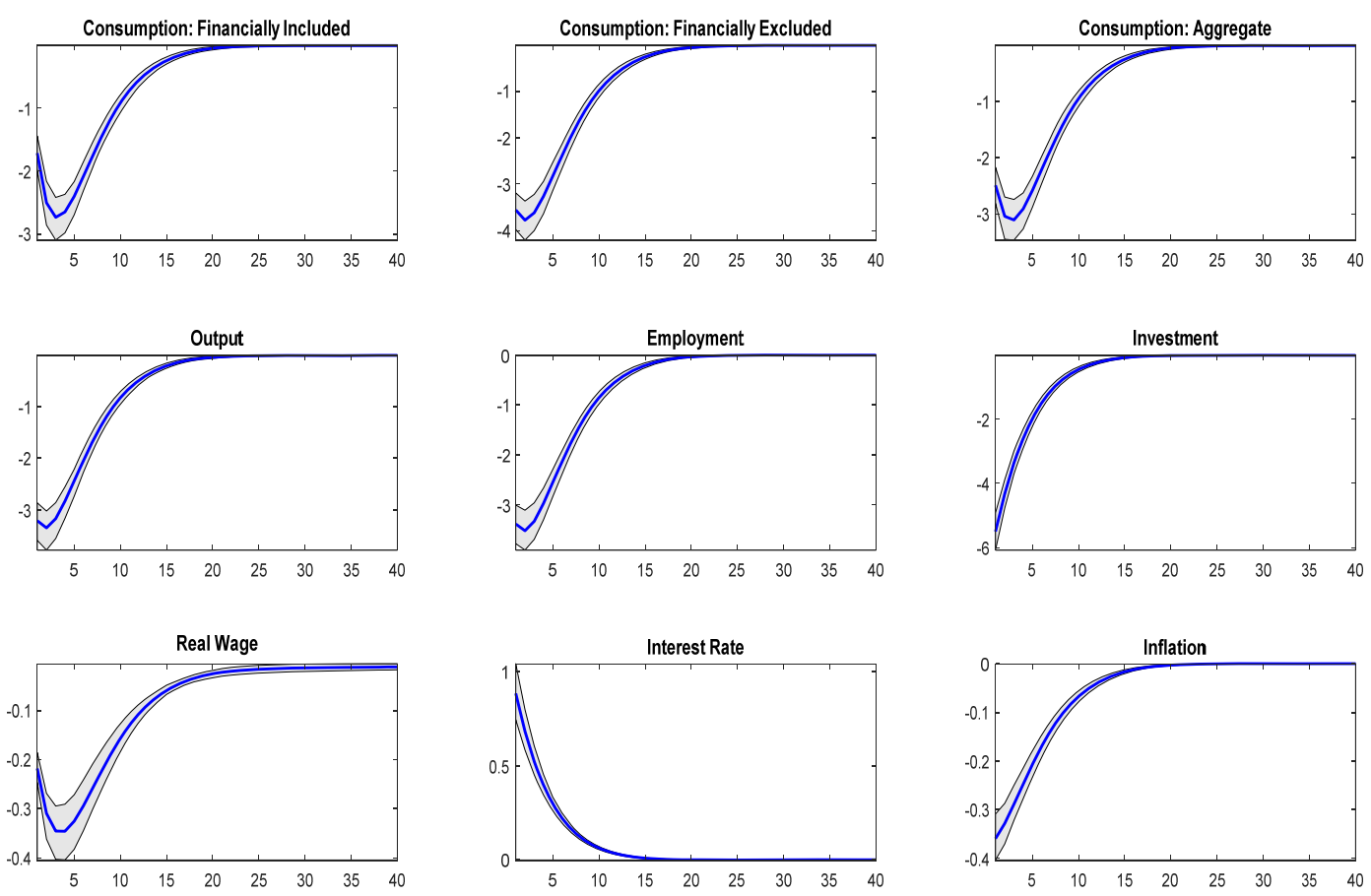

Figure 4: Monetary policy shock
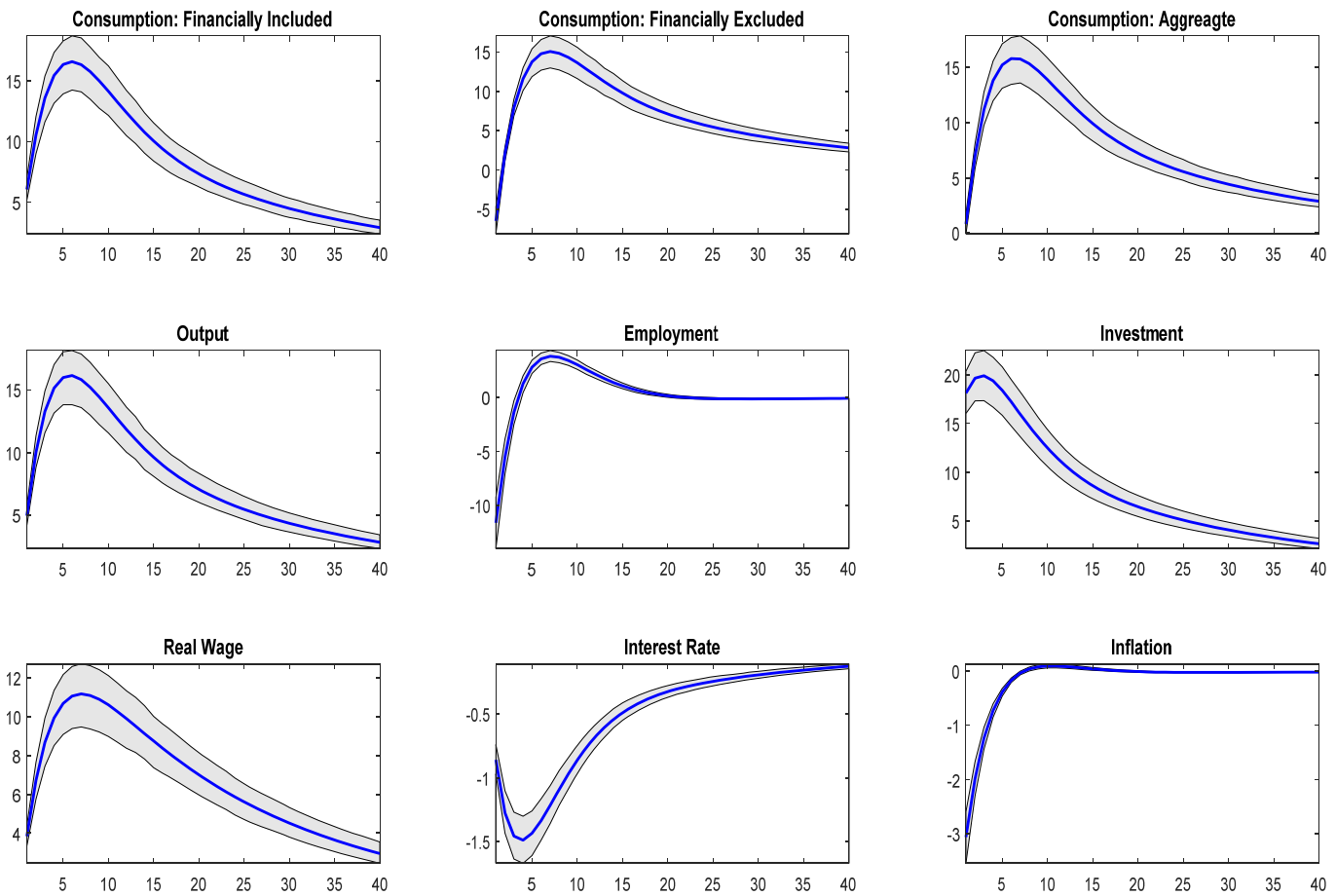

Figure 5: Technology shock 
In addition, the impulse responses of those macroeconomic variables to a positive labor supply shock are shown in Figure 7. That shock raises the marginal disutility of labor and plays a parallel role as wage mark-up shock. The shock raises the real wage to a peak of about 0.002 percentage points above its baseline value, inducing lower level of employment. Consequently, disposable income decreases leading to a reduction in the consumption of both types of households, though that of the financially excluded households saw an initial rise. It be observed that, the difference between their consumption levels is, however, not quantitatively large. Also, the increase in wage raises the marginal cost causing a rise in inflation. The monetary authorities through the Taylor rule moderate the inflationary pressures by increasing the nominal interest rate, inducing lower investment and a fall in output.
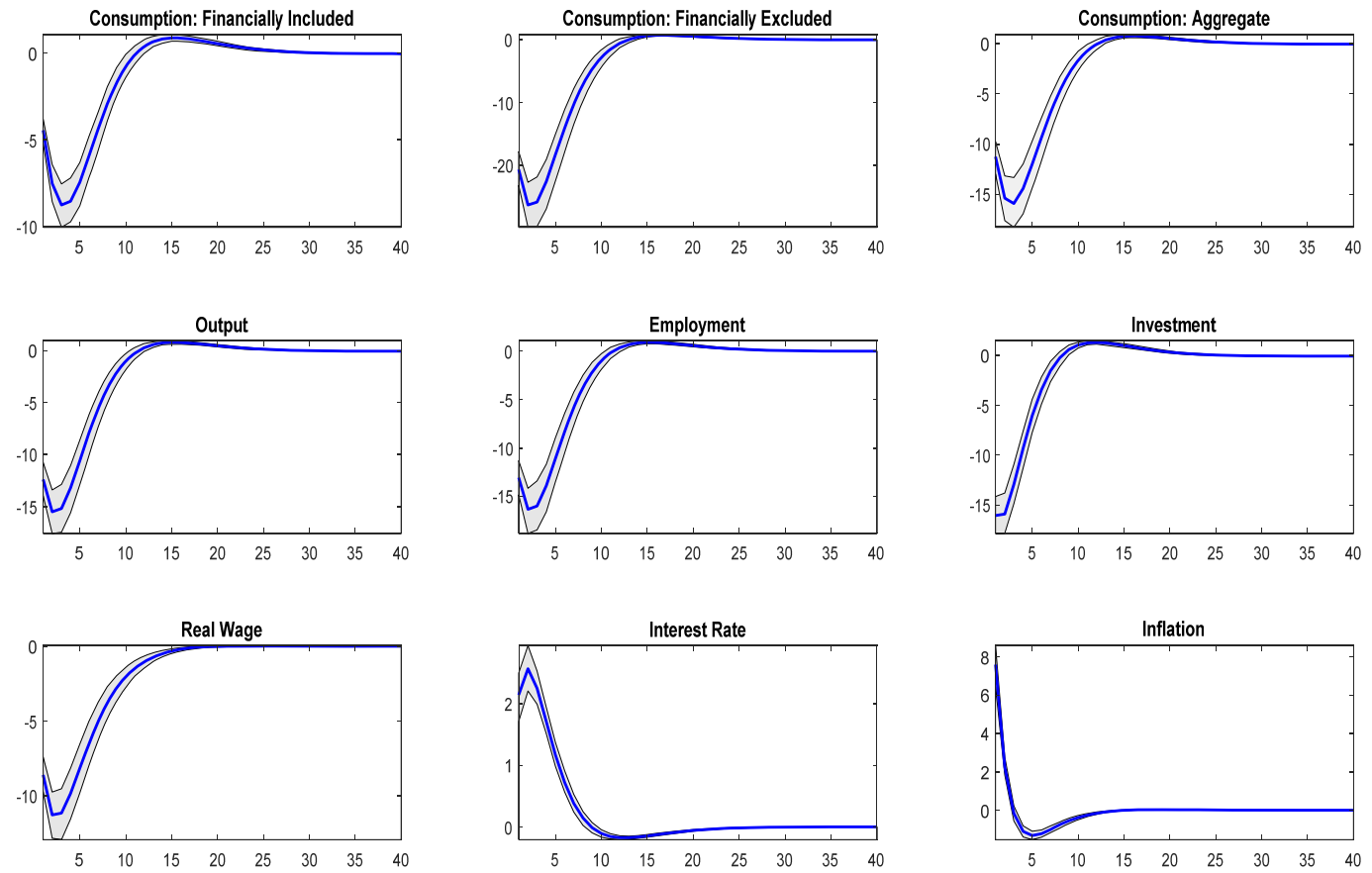

Figure 6: Price mark-up shock 

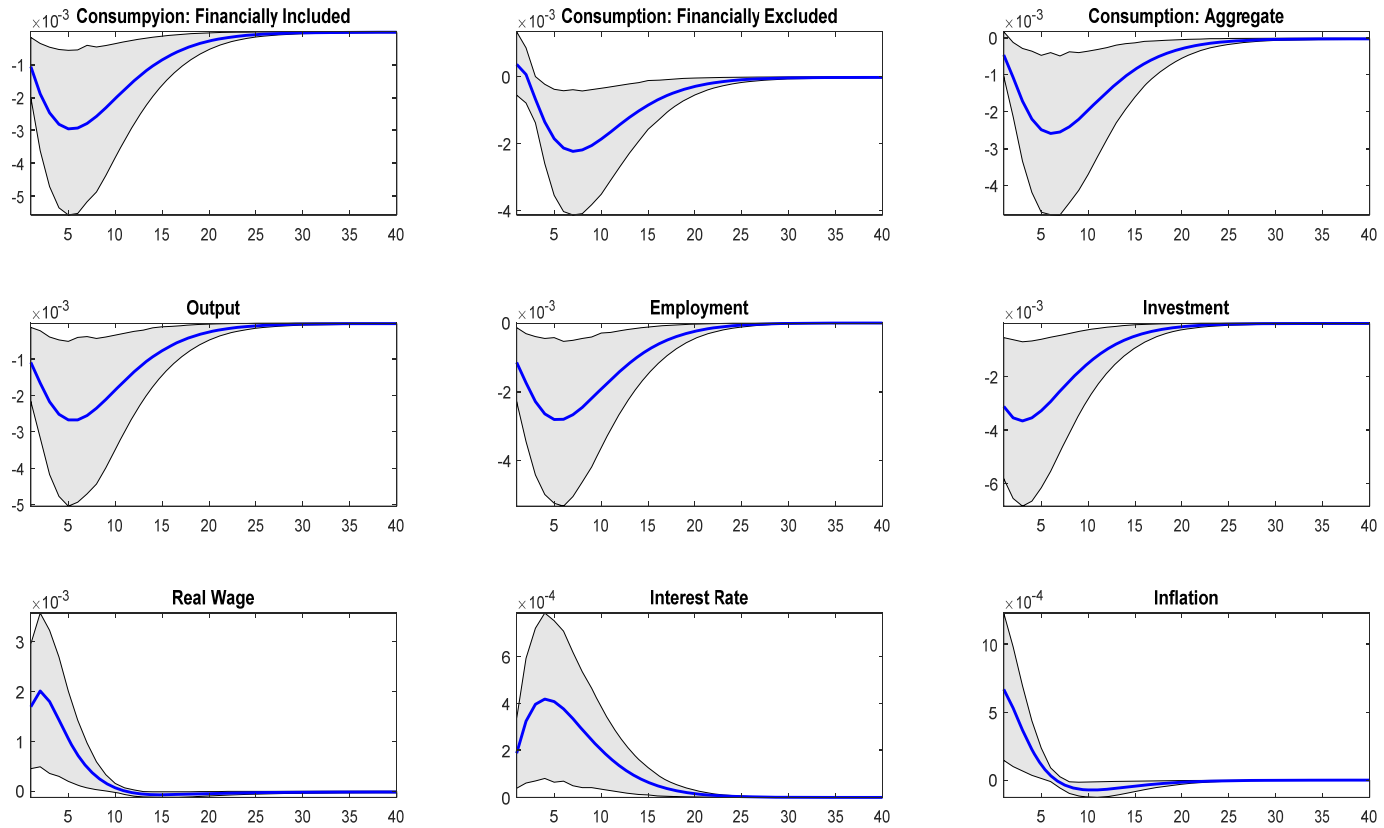

Figure 7: Labor supply shock

Finally, Figure 8 shows the effect of a positive preference (demand) shock. The exogenous increase in demand immediately increases output, consumption, and employment but crowds out investment. Consumption of both types of households increases, however, a larger rise in the consumption of financially excluded household is seen. This is because those households are able to borrow to increase consumption during, for example Christmas season (preference/demand shock). In particular, the consumption of financially included households immediately increases by about 6.69 percentage points and continues to rise until the third quarter, peaking at 9.2 percentage points above its steady state value. Similarly, the consumption of financially excluded households saw a rise of about 4.329 percentage points, continuing to surge until the third quarter where it reached a peak of about 6.19 percentage points. The increase in aggregate demand exerts upward pressure on the prices of inputs, and goods and services. Thus, nominal wage and inflation increase. However, the rise in nominal wage outweighs the rise in inflation. This is evidenced by a rise in real wage. Again, the monetary authorities control the inflationary pressures by increasing the nominal interest rate by about 0.16 percentage points, to a maximum of about 0.56 percentage points above its steady value as implied by the Taylor rule. 

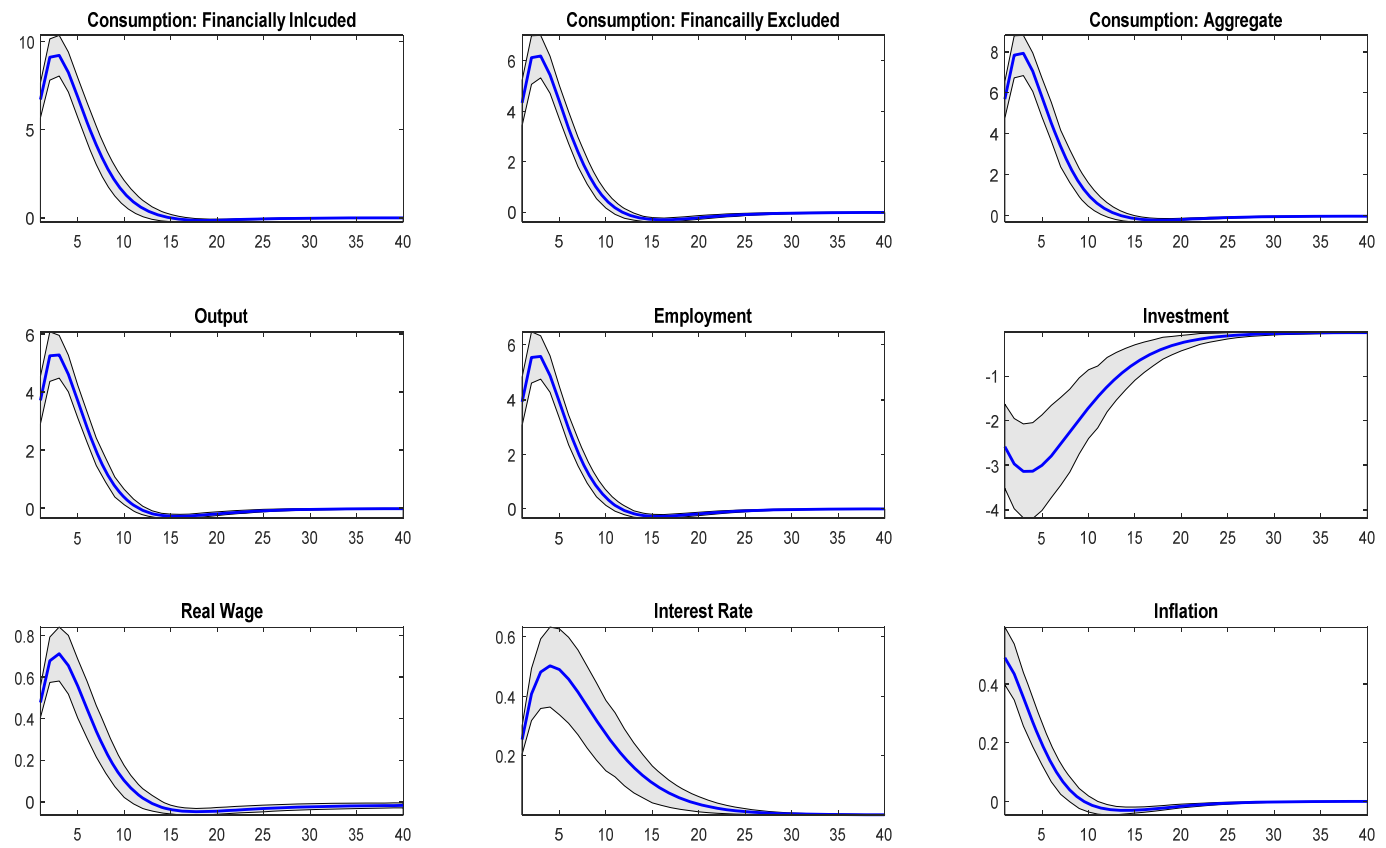

Figure 8: Preference shock

\subsection{Forecast Error Variance Decomposition}

Variance decomposition is performed to analyze the contribution of each of the structural shocks to the variations in output, consumption, employment, and inflation in the economy as a whole. The results at different horizons are reported in Tables 3 and 4 for each of country, with Table 3 for Ghana and Gabon, and Table 4 for Lesotho and Mauritius. Following Smet and Wouters (2003), we define 1-4 quarters (one year) as the short run, 10 quarters ( 2.5 years) as the medium run, and 100 quarters ( 25 years) as the long run. It can be seen that, the contribution of each of the structural shocks to the fluctuations in the real variables and inflation differ greatly among the countries. However, two conclusions stand out: whereas monetary policy shock appears to be moderately important in all countries at all horizons, labor supply shock contributes nothing to the variations in all the real variables and inflation in each country at all horizons.

In particular, the key drivers of output in the short, medium, and long term are technology, price mark-up, and monetary policy shocks in Ghana and in all the other countries. However, technology shock is seen to the main driver of output in all the countries at all horizons (about 70\%) except Lesotho, where price mark-up shock is the driver of output in the short and medium terms (about 60\%). Also, monetary policy shock moderately drives output in all countries at all horizons, usually ranging from $5 \%$ to $18 \%$ on average. In the short-run, it largely contributes to variations in output in Mauritius. Similar analysis and conclusion pertains to the fluctuations in consumption for all the countries.

With regard to the determinants of employment, monetary policy shock and price mark-up shock are found to be the most important drivers of employment in Ghana, Lesotho, and Mauritius but not Gabon, which has technology and price mark-up shocks 
dominating the driving of employment at all horizons. Among these three countries (Ghana, Lesotho, and Mauritius), monetary shock is the most contributor to employment variability in Mauritius, followed by Ghana and Lesotho. It can also be seen that the major drivers of employment at all horizons in Ghana are monetary policy and price mark-up shocks, with monetary policy shock less dominating.

Finally, considering the variability in inflation, monetary policy shock seems to be less important than price mark-up, technology, and preference shocks in all the countries at all horizons. Specifically, price mark-up and technology shocks are the most important contributors to inflation in all the countries at all horizons with the price mark-up shock largely dominating. It can be seen that price markup shock contributes the most to inflation variability in Ghana, about $78 \%$ and $76 \%$ in the medium and the long term, respectively.

\section{Conclusion and Policy Implications}

In this paper, we analyze the role and the impact of monetary policy shock along with other structural shocks on the consumption of financially included and excluded households in SSA economies. We adopt the standard New Keynesian DSGE model featuring both types of households, developed by Furlanetto and Seneca (2012). We introduce five structural shocks in addition to the productivity shock that is initially considered in the model to aid our analysis. Further, and in order to achieve our objective, we estimate the DSGE model using Bayesian inference methods for four middle-income SSA countries, namely: Ghana, Gabon, Lesotho, and Mauritius. This approach combines information from [1] the data from these countries over the period 1985 to 2016 and [2] our initial beliefs (priors) regarding the model's parameters for undertaking the estimation. The posterior estimates, the Bayesian impulse response functions, and the variance decomposition reveal several interesting insights regarding behavioral parameters, key macroeconomic variables, and structural shocks.

First, the estimates of the fraction of financially excluded households show that, comparatively, Ghana and Lesotho both have a higher level of financial inclusion than Mauritius and Gabon, i.e. about $65 \%$ of their citizens participate in the financial sector, followed by Mauritius (64\%). At the tail end is Gabon which has a relatively low level of financial inclusion (about 58\%). Overall, the fraction of financially excluded households is estimated to be relatively small.

Second, the parameter estimates in the Taylor rule suggest that monetary authorities in all the countries have been more aggressive towards inflation than output growth. Comparatively, monetary authorities in Ghana and Lesotho place relatively greater emphasis on inflation while Ghana, Gabon, and Mauritius place relatively larger emphasis on output growth. In addition, a considerable degree of interest-rate smoothing is estimated for Ghana and the other three countries.

Third, the Bayesian impulse response results are similar for all the countries and the analysis show that monetary policy shock negatively affects the consumption profile of financially excluded households more than financially included households. That is, a contractionary monetary policy worsens the welfare of financially excluded households more as compared with their counterparts, a finding which promotes or supports full financial inclusion agenda.

Fourth, the analysis of all the other four structural shocks signal that financially excluded households suffer more from 'unfavorable innovations" but benefit less from 
'favorable innovations': the reverse is true for financially included households. For example, a positive technology shock initially reduces the consumption of financially excluded households except with the passage of time (after about three quarters) that puts their consumption in a positive domain, while their financially included counterparts saw an immediate increase in their consumption. Thus, we have empirically confirm that, when households are faced with shocks financially excluded households experience higher volatility in their consumption than financially excluded ones.

Fifth, the variance decomposition analysis empirically confirms the importance of monetary policy in these economies. That is, the analysis has shown that monetary policy shock plays a rather key role in explaining the dynamics of the variations in key macroeconomic variables including output, consumption, employment, and inflation. However, price mark-up and technology shocks are the most important drivers of these variables, with labor supply shock not being important at all.

Finally, monetary policy plays a significant role (and is still effective) in SSA economies despite a sizeable fraction of the population being financially excluded. The impulse response analysis has evidenced the dynamics of the unfurling of monetary policy shock in these economies. Then, in line with economic theory and empirical evidence, a rise in the nominal interest rate brings about a fall in inflation and in all the real variables including output, employment, consumption, and investment.

From policy perspective, efforts to ensure full financial inclusion are recommended for monetary policy to continue playing its usual role. In addition, monetary authorities in developing countries need to place greater emphasis on output growth relative to inflation. This could support the stabilization of income, which would enable financially excluded households to smooth consumption. 


\section{References}

Beck, T., Demirguc-Kunt, A., Soledad, M., \& Peria, M. (2007). Reaching out: Access to and use of banking services across countries, Journal of Financial Economics, 85(1), 234-266.

Bilbiie, F. O. (2008). Limited asset markets participation, monetary policy and (inverted) aggregate demand logic. Journal of Economic Theory, 140(1), 162-196.

Brooks, S. P., \& Gelman, A. (1998). General methods for monitoring convergence of iterative simulations. Journal of Computational and Graphical statistics, 7(4), 434-455.

Brownbridge, M., Bwire, T., Rubatsimbira, D., \& Tinyinondi, G. A. (2017). The impact of Financial Inclusion on the interest rate channel of the monetary policy transmission mechanism. Bank of Uganda Working Paper No. 05.

Calvo, G. A. (1983). Staggered prices in a utility-maximizing framework. Journal of Monetary Economics, 12(3), 383-398.

Campbell, J. Y., \& Mankiw, N. G. (1989). Consumption, income, and interest rates: Reinterpreting the time series evidence. NBER Macroeconomics Annual, 4, 185216.

Campbell, J. Y., \& Mankiw, N. G. (1991). The response of consumption to income: A cross-country investigation. European Economic Review, 35(4), 723-756.

Cantah, W. G., \& Ahiakpor, F. (2017). Doves, hawks or pigeons? Characterising monetary policy regime switches in Ghana. African Finance Journal, 19(2), 4757.

Chow, G. C., \& Lin, A. L. (1971). Best linear unbiased interpolation, distribution, and extrapolation of time series by related series. The Review of Economics and Statistics, 372-375.

Christiano, L. J., Eichenbaum, M., \& Evans, C. L. (2005). Nominal rigidities and the dynamic effects of a shock to monetary policy. Journal of political Economy, 113(1), 1-45.

Christiano, L. J., Trabandt, M., \& Walentin, K. (2010). DSGE models for monetary policy analysis. In Handbook of Monetary Economics, 3, 285-367. Elsevier.

Coenen, G., \& Straub, R. (2005). Does government spending crowd in private consumption? Theory and empirical evidence for the euro area. International Finance, 8(3), 435-470.

Demirgüç-Kunt, A., \& Levine, R. (2009). Finance and inequality: Theory and evidence. Annu. Rev. Financ. Econ., 1(1), 287-318.

Demirguc-Kunt, A., Klapper, L., Singer, D., \& Oudheusden, P. V. (2015). The global findex database 2014: Measuring financial inclusion around the world. World Bank Policy Research Working Paper, 7255.

Demirguc-Kunt, A., Klapper, L., Singer, D., Ansar, S., \& Hess, J. (2018). The Global Findex Database 2017: Measuring Financial Inclusion and the Fintech Revolution. The World Bank.

Di Bartolomeo, G., Rossi, L., \& Tancioni, M. (2011). Monetary policy, rule-of-thumb consumers and external habits: a G7 comparison. Applied Economics, 43(21), 2721-2738

Forni, L., Monteforte, L., \& Sessa, L. (2009). The general equilibrium effects of fiscal policy: Estimates for the euro area. Journal of Public Economics, 93(3-4), 559585. 
Furlanetto, F., \& Seneca, M. (2012). Rule-of-thumb consumers, productivity, and hours. The Scandinavian Journal of Economics, 114(2), 658-679.

Galí, J., López-Salido J. D., \& Vallés, J. (2004): "Rule-of-thumb consumers and the design of interest rate rules,” Journal of Money, Credit and Banking 36(4), 739763.

Galí, J., López-Salido, J. D., \& Vallés, J. (2007). Understanding the effects of government spending on consumption. Journal of the European Economic Association, 5(1), 227-270.

Gomes, S., Iskrev, N., \& Mendicino, C. (2017). Monetary policy shocks: We got news! Journal of Economic Dynamics and Control, 74, 108-128.

Iyer, T. (2016). Optimal Monetary Policy in an Open Emerging Market Economy. Federal Reserve Bank of Chicago Working Papers 2016-06.

Jayachandran, S. (2006). Selling labor low: Wage responses to productivity shocks in developing countries. Journal of Political Economy, 114(3), 538-575.

Mankiw, N. G. (2000). The savers-spenders theory of fiscal policy. American Economic Review, 90(2), 120-125.

Marto, R. (2014). Assessing the impacts of non-ricardian households in an estimated new Keynesian DSGE model. Swiss Journal of Economics and Statistics, 150(4), 353398.

Mehrotra, A. N., \& Yetman, J. (2014). Financial inclusion and optimal monetary policy. Bank for International Settlements (BIS) Working Papers No. 476.

Mehrotra, A., \& Nadhanael, G. V. (2016). Financial Inclusion and Monetary Policy in Emerging Asia. In Financial Inclusion in Asia (pp. 93-127). Palgrave Macmillan, London.

Papadvid, P. (2016). Broadening financial inclusion in sub-Saharan Africa. macroeconomic impact series. Retrieved from https://www.odi.org/sites/ odi.org.uk/files/resource-documents/ 10958.pdf.

Ratto, M., Roeger, W., \& in't Veld, J. (2009). QUEST III: An estimated open-economy DSGE model of the euro area with fiscal and monetary policy. Economic Modelling, 26(1), 222-233

Rosenzweig, M. R., \& Wolpin, K. I. (1993). Credit market constraints, consumption smoothing, and the accumulation of durable production assets in low-income countries: Investments in bullocks in India. Journal of Political Economy, 101(2), 223-244.

Rotemberg, J. J. (1982). Monopolistic price adjustment and aggregate output. The Review of Economic Studies, 49(4), 517-531.

Smets, F., \& Wouters, R. (2003). An estimated dynamic stochastic general equilibrium model of the euro area. Journal of the European Economic Association, 1(5), 1123-1175.

Smets, F., \& Wouters, R. (2007). Shocks and frictions in US business cycles: A Bayesian DSGE approach. American Economic Review, 97(3), 586-606.

Taylor, J. B. (1993, December). Discretion versus policy rules in practice. In CarnegieRochester conference series on public policy, 39,195-214, North-Holland. 
TABLES

Table 1: Bayesian Estimation results for Ghana and Gabon

\begin{tabular}{|c|c|c|c|c|c|c|}
\hline \multicolumn{2}{|c|}{ Estimated Parameters } & \multicolumn{3}{|c|}{ Prior } & \multicolumn{2}{|c|}{ Posterior } \\
\hline & & \multicolumn{3}{|c|}{ Both countries } & Ghana & Gabon \\
\hline & & Distribution & Mean & St. Dev & Mean & Mean \\
\hline \multicolumn{7}{|c|}{ Households } \\
\hline Financially excluded & $\lambda$ & Beta & 0.5 & $\begin{array}{l}0.025 \\
{[0.02]}\end{array}$ & 0.3509 & 0.4184 \\
\hline Consumption habit & $h$ & Beta & 0.7 & $\begin{array}{l}0.025 \\
{[0.02]}\end{array}$ & 0.6590 & 0.6833 \\
\hline Discount factor & $\beta$ & Beta & 0.99 & 0.002 & 0.9907 & 0.9935 \\
\hline Depreciation Rate & $\delta$ & Beta & 0.025 & 0.003 & 0.0249 & 0.0169 \\
\hline \multicolumn{7}{|c|}{ Firms/Labor Union } \\
\hline Share of capital & $\alpha$ & Beta & 0.33 & 0.1 & 0.0423 & 0.0500 \\
\hline Degree price stickiness & $\theta$ & Beta & 0.75 & 0.01 & 0.7499 & 0.7500 \\
\hline Frisch labor elasticity & $\phi$ & Gamma & 0.500 & 0.01 & 0.4988 & 0.4994 \\
\hline \multicolumn{7}{|c|}{ Monetary Policy (Taylor Rule) } \\
\hline $\begin{array}{l}\text { Degree of interest-rate } \\
\text { smoothing }\end{array}$ & $\rho_{r}$ & Beta & 0.69 & 0.1 & 0.5350 & 0.8952 \\
\hline Inflation & $\phi_{\pi}$ & Normal & 1.7 & 0.25 & 3.2507 & 3.0972 \\
\hline Output growth & $\phi_{y}$ & Normal & 0.26 & 0.015 & 0.2473 & 0.2441 \\
\hline \multicolumn{7}{|c|}{ Shocks } \\
\hline \multicolumn{7}{|c|}{ Persistence } \\
\hline Technology & $\rho_{a}$ & Beta & 0.95 & 0.002 & 0.9551 & 0.9560 \\
\hline Preference & $\rho_{b}$ & Beta & 0.5 & 0.1 & 0.8913 & 0.7349 \\
\hline Price mark-up & $\rho_{p}$ & Beta & 0.5 & 0.1 & 0.4746 & 0.5651 \\
\hline Labor supply & $\rho_{l}$ & Beta & 0.5 & 0.1 & 0.4994 & 00.4985 \\
\hline \multicolumn{7}{|c|}{ St. Dev of shocks } \\
\hline Technology & $\sigma_{a}$ & inv_gamma & 0.1 & 2 & 9.5605 & 16.7224 \\
\hline Monetary policy & $\sigma_{m}$ & inv_gamma & 0.1 & 2 & 6.0659 & 1.0874 \\
\hline Preference & $\sigma_{b}$ & inv_gamma & 0.1 & 2 & 19.5148 & 25.1920 \\
\hline Price mark-up & $\sigma_{p}$ & inv_gamma & 0.1 & 2 & 43.5209 & 71.6747 \\
\hline Labor supply & $\sigma_{l}$ & inv_gamma & 0.1 & 2 & 0.0995 & 0.0945 \\
\hline
\end{tabular}


Table 2: Bayesian Estimation results for Lesotho and Mauritius

\begin{tabular}{|c|c|c|c|c|c|c|}
\hline \multicolumn{2}{|c|}{ Estimated Parameters } & \multicolumn{3}{|c|}{ Prior } & \multicolumn{2}{|c|}{ Posterior } \\
\hline & & \multicolumn{3}{|c|}{ Both countries } & \multirow{2}{*}{$\begin{array}{c}\text { Lesotho } \\
\text { Mean }\end{array}$} & \multirow{2}{*}{$\begin{array}{c}\text { Mauritius } \\
\text { Mean }\end{array}$} \\
\hline & & Distribution & Mean & $\begin{array}{l}\text { St. } \\
\text { Dev }\end{array}$ & & \\
\hline \multicolumn{7}{|c|}{ Households } \\
\hline Financially excluded & $\lambda$ & Beta & 0.5 & 0.025 & 0.3462 & 0.3604 \\
\hline Consumption habit & $h$ & Beta & 0.7 & 0.025 & 0.5327 & 0.6939 \\
\hline Discount factor & $\beta$ & Beta & 0.99 & 0.002 & 0.9919 & 0.9903 \\
\hline Depreciation & $\delta$ & Beta & 0.025 & 0.003 & 0.0206 & 0.0271 \\
\hline \multicolumn{7}{|c|}{ Firms/Labor Union } \\
\hline Share of capital & $\alpha$ & Beta & 0.33 & 0.1 & 0.0308 & 0.0553 \\
\hline $\begin{array}{l}\text { Degree price } \\
\text { stickiness }\end{array}$ & $\theta$ & Beta & 0.75 & $\begin{array}{l}0.015 \\
{[0.1]}\end{array}$ & 0.7508 & 0.7491 \\
\hline Frisch labor elasticity & $\phi$ & Gamma & 0.5 & 0.1 & 0.3437 & 0.4983 \\
\hline \multicolumn{7}{|c|}{ Monetary Policy (Taylor Rule) } \\
\hline $\begin{array}{l}\text { Degree of interest-rate } \\
\text { smoothing }\end{array}$ & $\rho_{r}$ & Beta & 0.69 & 0.1 & 0.6715 & 0.6525 \\
\hline Inflation & $\phi_{\pi}$ & Normal & 1.7 & 0.25 & 3.2619 & 3.1578 \\
\hline Output growth & $\phi_{y}$ & Normal & 0.26 & $\begin{array}{c}0.015 \\
{[0.025]}\end{array}$ & 0.2319 & 0.2434 \\
\hline \multicolumn{7}{|c|}{ Shocks } \\
\hline \multicolumn{7}{|c|}{ Persistence } \\
\hline Technology & $\rho_{a}$ & Beta & 0.95 & 0.002 & 0.9524 & 0.9565 \\
\hline Preference & $\rho_{b}$ & Beta & 0.5 & 0.1 & 0.9514 & 0.7572 \\
\hline Price mark-up & $\rho_{p}$ & Beta & 0.5 & 0.1 & 0.1291 & 0.4177 \\
\hline Labor supply & $\rho_{l}$ & Beta & 0.5 & 0.1 & 0.4961 & 0.5013 \\
\hline \multicolumn{7}{|c|}{ St. Dev of shocks } \\
\hline Technology & $\sigma_{a}$ & inv_gamma & 0.1 & 2 & 7.7842 & 6.8386 \\
\hline Monetary policy & $\sigma_{m}$ & inv_gamma & $\begin{array}{c}0.1 \\
{[0.01]}\end{array}$ & 2 & 5.6415 & 4.4745 \\
\hline Preference & $\sigma_{b}$ & inv_gamma & 0.1 & 2 & 31.3097 & 10.9759 \\
\hline Price mark-up & $\sigma_{p}$ & inv_gamma & 0.1 & 2 & 138.1387 & 20.7065 \\
\hline Labor supply & $\sigma_{l}$ & inv_gamma & 0.1 & 2 & 0.0733 & 0.1118 \\
\hline
\end{tabular}


Table 3: Forecast Error Variance Decomposition (in percent) for Ghana and Gabon

\begin{tabular}{|c|c|c|c|c|c|c|c|c|}
\hline & \multicolumn{2}{|c|}{ Output } & \multicolumn{2}{|c|}{ Consumption } & \multicolumn{2}{|c|}{ Employment } & \multicolumn{2}{|c|}{ Inflation } \\
\hline Shocks & GH & GA & GH & GA & GH & GA & GH & GA \\
\hline \multicolumn{9}{|c|}{ Forecast horizon: $1^{\text {st }}$ Quarter } \\
\hline Monetary Policy & 8.20 & 5.16 & 7.11 & 3.79 & 27.47 & 3.52 & 0.68 & 0.20 \\
\hline Technology & 73.19 & 12.30 & 69.83 & 0.62 & 10.53 & 40.34 & 13.62 & 14.06 \\
\hline Price Mark-up & 18.04 & 75.58 & 17.35 & 75.78 & 60.15 & 51.47 & 81.23 & 85.37 \\
\hline Preference & 0.56 & 6.96 & 5.71 & 19.81 & 1.85 & 4.67 & 4.47 & 0.37 \\
\hline Labor Supply & 0.00 & 0.00 & 0.00 & 0.00 & 0.00 & 0.00 & 0.00 & 0.00 \\
\hline \multicolumn{9}{|c|}{ Forecast horizon: $4^{\text {th }}$ Quarter } \\
\hline Monetary Policy & 11.98 & 2.75 & 11.43 & 2.37 & 25.68 & 3.72 & 0.49 & 0.48 \\
\hline Technology & 56.80 & 36.27 & 50.34 & 25.57 & 7.73 & 14.12 & 18.42 & 19.19 \\
\hline Price Mark-up & 30.81 & 54.68 & 33.54 & 57.42 & 65.69 & 73.64 & 78.97 & 79.51 \\
\hline Preference & 0.41 & 6.30 & 4.69 & 14.64 & 0.89 & 8.53 & 2.12 & 0.82 \\
\hline Labor Supply & 0.00 & 0.00 & 0.00 & 0.00 & 0.00 & 0.00 & 0.00 & 0.00 \\
\hline \multicolumn{9}{|c|}{ Forecast horizon: 10 $^{\text {th }}$ Quarter } \\
\hline olicy & 7.40 & 1.83 & 6.66 & 1.68 & 24.05 & 4.03 & 0.52 & 0.58 \\
\hline Technology & 73.68 & 61.29 & 69.98 & 53.88 & 14.41 & 15.16 & 18.43 & 18.14 \\
\hline Price Mark-up & 18.45 & 33.00 & 18.35 & 35.46 & 59.94 & 72.20 & 77.56 & 80.42 \\
\hline Preference & 0.47 & 3.88 & 5.02 & 8.98 & 1.60 & 8.61 & 3.49 & 0.85 \\
\hline Labor Supply & 0.00 & 0.00 & 0.00 & 0.00 & 0.00 & 0.00 & 0.00 & 0.00 \\
\hline \multicolumn{9}{|c|}{ Forecast horizon: 100 $^{\text {th }}$ Quarter } \\
\hline Monetary Policy & 5.54 & 1.27 & 4.86 & 1.17 & 23.65 & 4.03 & 0.52 & 0.59 \\
\hline Technology & 80.06 & 73.37 & 77.27 & 68.49 & 14.60 & 16.05 & 18.41 & 18.15 \\
\hline Price Mark-up & 13.99 & 22.69 & 13.61 & 24.22 & 59.96 & 71.41 & 76.88 & 80.40 \\
\hline Preference & 0.41 & 2.66 & 4.26 & 6.12 & 1.79 & 8.50 & 4.20 & 0.86 \\
\hline Labor Supply & 0.00 & 0.00 & 0.00 & 0.00 & 0.00 & 0.00 & 0.00 & 0.00 \\
\hline
\end{tabular}

Note: GH stands for Ghana whereas GA stands for Gabon 
Table 4: Forecast Error Variance Decomposition (in percent) for Lesotho and Mauritius

\begin{tabular}{|c|c|c|c|c|c|c|c|c|}
\hline & \multicolumn{2}{|c|}{ Output } & \multicolumn{2}{|c|}{ Consumption } & \multicolumn{2}{|c|}{ Employment } & \multicolumn{2}{|c|}{ Inflation } \\
\hline Shocks & LES & MAU & LES & MAU & LES & MAU & LES & MAU \\
\hline \multicolumn{9}{|c|}{ Forecast horizon: $1^{\text {st }}$ Quarter } \\
\hline Monetary Policy & 18.35 & 50.03 & 16.09 & 49.65 & 20.18 & 40.78 & 0.14 & 1.65 \\
\hline Technology & 9.36 & 27.74 & 5.14 & 13.69 & 0.45 & 45.18 & 1.94 & 26.84 \\
\hline Price Mark-up & 71.25 & 20.48 & 77.45 & 25.13 & 78.21 & 11.82 & 97.71 & 70.50 \\
\hline Preference & 1.04 & 1.76 & 1.31 & 11.53 & 1.15 & 2.22 & 0.21 & 1.01 \\
\hline Labor Supply & 0.00 & 0.00 & 0.00 & 0.00 & 0.00 & 0.00 & 0.00 & 0.00 \\
\hline \multicolumn{9}{|c|}{ Forecast horizon: $4^{\text {th }}$ Quarter } \\
\hline Monetary Policy & 18.00 & 27.14 & 16.63 & 25.96 & 24.88 & 58.23 & 0.32 & 3.14 \\
\hline Technology & 29.86 & 57.66 & 25.06 & 49.91 & 3.44 & 8.93 & 3.11 & 35.69 \\
\hline Price Mark-up & 51.33 & 11.96 & 54.37 & 13.22 & 70.57 & 25.76 & 95.85 & 58.80 \\
\hline Preference & 0.81 & 3.25 & 3.93 & 10.91 & 1.11 & 7.08 & 0.73 & 2.37 \\
\hline Labor Supply & 0.00 & 0.00 & 0.00 & 0.00 & 0.00 & 0.00 & 0.00 & 0.00 \\
\hline \multicolumn{9}{|c|}{ Forecast horizon: $10^{\text {th }}$ Quarter } \\
\hline Monetary Policy & 14.23 & 15.83 & 13.13 & 14.56 & 24.51 & 53.57 & 0.36 & 3.43 \\
\hline Technology & 45.36 & 75.30 & 41.93 & 71.58 & 6.34 & 15.95 & 3.16 & 35.54 \\
\hline Price Mark-up & 38.92 & 6.35 & 39.63 & 6.45 & 66.69 & 21.71 & 95.11 & 58.11 \\
\hline Preference & 1.48 & 2.51 & 5.31 & 7.41 & 2.46 & 8.77 & 1.38 & 2.92 \\
\hline Labor Supply & 0.00 & 0.00 & 0.00 & 0.00 & 0.00 & 0.00 & 0.00 & 0.00 \\
\hline \multicolumn{9}{|c|}{ Forecast horizon: $\mathbf{1 0 0}^{\text {th }}$ Quarter } \\
\hline Monetary Policy & 12.12 & 11.18 & 11.18 & 10.03 & 23.57 & 53.03 & 0.35 & 3.43 \\
\hline Technology & 51.20 & 82.50 & 48.62 & 80.33 & 6.31 & 16.39 & 3.15 & 35.68 \\
\hline Price Mark-up & 33.56 & 4.54 & 34.20 & 4.50 & 64.94 & 21.79 & 94.38 & 57.94 \\
\hline Preference & 3.13 & 1.78 & 6.01 & 5.15 & 5.18 & 8.79 & 2.11 & 2.95 \\
\hline Labor Supply & 0.00 & 0.00 & 0.00 & 0.00 & 0.00 & 0.00 & 0.00 & 0.00 \\
\hline
\end{tabular}

Note: LSO stands for Lesotho and MUS stands for Mauritius 